\title{
The Role of Geospatial Industrial Diversity in the Facilitation of Regional Industrial Symbiosis
}

\author{
Paul D. Jensen ${ }^{a, b}$ \\ ${ }^{a}$ National Industrial Symbiosis Programme, Birmingham, West Midlands, UK \\ ${ }^{\mathrm{b}}$ Centre for Environmental Strategy, University of Surrey, Guildford, Surrey, UK
}

\begin{abstract}
This paper explores geospatial industrial diversity and its influence on the brokerage of industrial symbiosis working agreements (otherwise known as synergies). Research conducted in 2011 concluded that within third-party brokered resource exchanges between two or more normally unrelated companies, the industrial diversity of a given geographic area was the primary driver behind how far a material travels from its point of origin to its point of reuse. This conclusion was largely derived from intuition and the elimination of other widely discussed drivers or limitations to symbiotic resource movement (e.g., mental distances, resource value and/or the physical characteristics of a resource). The presented article sets out to empirically test this suggestion by mapping the geospatial industrial diversity of England and comparing it to the movement of resources within synergies facilitated by the National Industrial Symbiosis Programme (NISP). Among other results, it was established that there are correlations between geospatial industrial diversity and the distance materials move in addition to the number of synergy types and the replication of synergies facilitated within a given area. It was found that $76 \%$ of synergies were facilitated within areas of high (upper $10 \%$ of values) contiguous diversity, areas of high 'species' richness possessed a greater variety of synergies, and areas of high synergy replication were areas of high 'species' population evenness. Based on a sensitivity analysis of diversity indices and diversity mapping techniques, it was concluded that high 'species' richness provided the greatest opportunities for realising local industrial symbiosis.
\end{abstract}




\section{Introduction}

It has been argued that industrial ecologists should empirically explore the development of what are seen to be 'desirable' and increasingly needed aspects of nature, such as resource recycling, productive efficiency, and/or system resilience, before attempting to prescribe or 'mimic' them in the design and development of industrial ecosystems (see Jensen et al., 2011a). One particular observation of nature which has drawn much attention within industrial ecology is the concept of diversity and the many beneficial effects of its presence within a given locale. In orthodox ecology it has been argued that increased diversity has positive effects on system production (e.g.,Tilman et al. 2001; Hooper et al., 2005; Flombaum and Sala, 2008); whilst suggestions that a diversity of system actors can promote resource efficiency and system resilience have existed within ecological research circles for many years ${ }^{1}$. As such, it is readily apparent why diversity should be a concept of interest within industrial ecology research. Indeed, the subject of diversity within industrial ecosystems has already been afforded dedicated examination by several authors (e.g., Korhonen, 2005; Wells and Darby, 2006; Wright et al., 2009); whilst the concept is given more than a passing consideration within many further industrial ecology focussed articles (e.g., Korhonen, 2001; Nielsen, 2007; Mayer, 2008; Ashton, 2009; Jensen et al., 2011a). Many of these articles are largely conceptual in nature and approach the subject of diversity and its potential for promoting the development of sustainable and resourceful industrial systems from a theoretical and assumptive position. Keeping in mind that industrial ecology is still a nascent discipline, there is nothing intrinsically wrong with this form of analysis and each article, in its own way, provides a stepping stone toward the greater depth of understanding required to elevate industrial ecology to a position where it can deliver tangible eco-industrial development. However, as stated by Wright et al. (2009), ecology is largely a quantitative science. Indeed, orthodox ecology is a science based upon observation, analysis, and interpretation into sound context-specific scientific principle. Thus, the actual role that diversity plays within the development and functioning of an industrial ecosystem must be ascertained through empirical observation and analysis before it is promoted as a desirable aspect of sustainable or resource efficient industrial development.

This paper continues by further exploring the concept of diversity and its effects on system functioning. The specific context of this discussion is that of understanding the role industrial diversity plays in providing opportunities for resource efficiency. Using a geographic information system (GIS) and novel industry type sampling techniques, an empirical study was conducted into the geospatial industrial diversity of England and the role it played in the facilitation of industrial symbiosis working agreements (brokered by the United Kingdom's National Industrial Symbiosis Programme [NISP]). Correlations between the presence of resource synergies and the industrial diversity surrounding the resource partners were tested. The results of this study, which is unique in the context of industrial ecology, are presented and discussed in relation to understanding how geospatial industrial diversity affects resource movement, how diversity affects industrial ecosystem productivity, and how study findings can be employed in proactive attempts to implement eco-industrial development. By way of conclusion, the article provides options for developing the diversity mapping methodology in addition to suggesting

\footnotetext{
${ }^{1}$ Though see Yue et al. (2005) for an overview of the many debates on the relationships between diversity and ecosystem functioning and see Hooper et al. (2005) for a "consensus of current knowledge" on the subject of biodiversity and ecosystem functioning.
} 
avenues for further essential research into the development of functional diversity and niche based diversity indices.

\section{2. 'Diversity' and its Evolution}

Diversity is a highly relative concept and its effects in a given ecosystem are invariably idiosyncratic (Jensen et al. 2011a). Due to the many semantic, conceptual and technical problems involved in the study of diversity it can, in some contexts, be deemed to be a 'non-concept' (Hurlbert 1971). As such, what does diversity mean and what is meant by its effects in a given system? Diversity, at its most basic, is the richness of species within a sampled area (e.g., the number of distinctly different individuals) ${ }^{2}$. This meaning of diversity is further developed when considered in relation to the equability, or evenness, of the total population of each sampled species. For instance, a sampled geographic area which possesses 30 individuals, consisting of three species with equal populations of 10 individuals, is ordinarily deemed to be more diverse than a sampled area that possesses a population of 28 individuals of one species and one each of two further species. Although both sampled areas contain 30 organisms and three distinct species, the former area is more equitable in terms of the populations that compose the area's community than that of the latter area's community which is dominated by one species. To assess community evenness in a more sophisticated manner, and make measurements of evenness diversity comparable to other communities, indices (or indexes) have been devised which allow comparison between sampled areas by measuring evenness on normalised scales (e.g., Simpson, 1949). Whether, however, these basic definitions of diversity and the many (further) ways it can be measured and compared are meaningful or useful has, within orthodox ecology, been a debate in its own right (e.g. Hurlbert, 1971; Jost, 2006).

Indeed, it is essential to note that all species are not equal in their effects on ecosystem functioning (Mouchet et al., 2010); and some are more competitive or simply more fecund than others. As a consequence of these facts, some of the key discussion points within ecological research revolve around understanding the specific role a given species plays within an ecosystem and duly the concepts of functional and redundant diversity (and, paradoxically, functional-redundancy). In very simple terms, functional diversity refers to a species or a collection of species that perform a function within a given community which directly supports other species or a process that is essential to the ongoing functioning of the ecosystem (these species are sometimes termed 'keystone' species). Redundant diversity, meanwhile, postulates that some species fill the same or similar roles within an ecosystem and consequently the loss of one of these species would have little or no immediate impact on their community and wider system functioning ${ }^{3}$. These two forms of diversity, and how they intrinsically affect how we latterly conceptualise diversity and the ostensibly positive ecosystem properties that they help to generate, are extremely important. For the level of analyses presented in this paper, however, the simple definition and distinction between functional and redundant diversity, provided

\footnotetext{
${ }^{2}$ This definition, however, can be further expanded to refer to diversity at all levels of biological structure, from gene through to the given example of species through to the diversity of phenotypes (and so on).

${ }^{3}$ It has been claimed that redundancy of species contributes to, among other system properties, insurance against ecosystem collapse (i.e. system stability). Thus, it should not be assumed that the lack of a unique function within an ecosystem makes a given species any less valuable than one that could be deemed to be 'functional' (see Yachi and Loreau [1999] and Loreau [2000] and their associated references).
} 
above, are adequate (for a more detailed elucidation of these points, however, see Hooper et al. [2005] and Begon et al. [2006])

The apparent effects of system 'diversity' that, from an anthropogenic viewpoint, are deemed to be desirable (e.g., increased recycling, productivity and system resilience), largely emerge from the processes which also promote the evolution of ecosystem diversity. Effectively, greater localised diversity is a result of increased local resource availability and usage pathways, both in a spatial and temporal sense. The increase in resource availability and pathways for reuse and recycling of resources derive from the processes of niche construction, facilitation and realisation (as promoted by, among other processes, system succession). For example, pioneer species that colonise and proliferate in seemingly bare earth create, by their very appearance, niches for further species of biota to eventually colonise a given area. This continual (actionreaction or cause-effect) process of system evolution leads to feedback controls and processes which shape an ecosystem and its constituent elements. As an ecosystem develops and fundamental niches are realised by a given species ${ }^{4}$, or a species evolves to fill a niche, complementarity, competition and niche partitioning amongst species develops and resource efficiency and recycling invariably increases along with system productivity (see Odum [1969] for a general background to ecosystem succession). This process of ecosystem diversification and the evolution of each species' fundamental and specific niches are arguably applicable to any form of system, including industrial systems. Agglomeration economies and other theories relating to industrial clustering which derive from the field of economic geography, largely translate as basic niche construction and realisation theory within biological ecology's understanding of the evolution of mutually beneficial (and competitive) interactions (see Renner [1947], Nielsen [2007], Mayer [2008], Belussi and Caldari [2009], Nielsen and Müller [2009] for discussions that compliment and contrast this supposition).

The observed extent of diversity within a particular area is dictated by the spatial and temporal levels of resource availability, levels of resource competition and, consequently, levels of realised niche overlap between incumbent system species (Begon et al. 2006). As such, diversity within one area could be wrongly deemed to be low in comparison to another if considerations of ecosystem specifics and species function are not taken into account. For instance, in comparison to the tropics, the terrestrial biota of the Arctic and Antarctic regions could be deemed to be minimal. However, in relation to the comparative availability of life sustaining resources, such as sunlight, fresh water, and primary production, the levels of biological diversity found within the Polar Regions could be seen to be remarkably high. Levels of diversity are ultimately dictated by prevailing local environmental conditions (Jensen et al. 2011a), and not by a basic cognitive interpretation of one number being larger than another. In turn, the emergent system properties of resource cycling, increased productivity and system resilience, which from an industrial ecology perspective are deemed to be beneficial, are largely present in an idiosyncratic manner and dictated by the specific components and environmental conditions of a particular system.

\section{Industrial Symbiosis and Industrial Diversity}

\footnotetext{
${ }^{4}$ Fundamental niche and realised niche refers, respectively, to all niches that a given organism can fill in the absence of competition and the specific (observed) niche a given organism does fill.
} 
Industrial symbiosis can be seen as the establishment of close working agreements between normally unrelated industrial (and/or other) organisations that leads to resource efficiency (Jensen et al., 2011b). The most common example of an industrial symbiosis working agreement, otherwise known as a synergy, is the operational waste products from one industry being reused as a raw material by a company from another industry. The economic and environmental benefits that can be derived from such symbiotic resource exchanges (in the form of landfill diversion, raw material savings, carbon savings, cost savings and new sales) have been shown to be significant (Laybourn and Morrissey, 2009; Lombardi and Laybourn, 2012). Consequently, much research into the phenomena of industrial symbiosis and the various ways in which symbiosis has or can be implemented have been conducted (e.g. Chertow, 2000, 2007; Mirata, 2004; Gibbs 2008; Costa and Ferrão, 2010; Velenturf and Jensen, 2014).

Similarly to research conducted on biological system functioning, it has been argued that a diversity of industries provide the collective functions and adaptability within an industrial ecosystem that are essential to its continued functioning and stability (e.g. Côté and Smolenaars 1997; Korhonen 2001; Ashton 2009). It has also similarly been surmised that an increase in potential resource pathways, which derive from an increase in system diversity, promotes opportunities for localised by-product reuse and thus increased productivity (e.g. Korhonen 2001; Hardy and Graedel 2002; Korhonen and Snäkin 2005; Liwarska-Bizukojc et al. 2009).

One diversity related study into the subject of industrial symbiosis and, specifically, the brokered facilitation of synergies within the United Kingdom, found that the physical by-products of a company moved, on average, 32.6 kilometres $(\mathrm{km})$ to a point of reuse by a symbiont company belonging to an unrelated industry (see Jensen et al. 2011b). The study by Jensen et al. (2011b) provided empirical evidence to suggest that the relatively short distances materials moved to a point of reuse was not attributable to the physical characteristics of the resource (in relation to its size, shape or weight), its monetary value, or the environmental cost of transporting the resources. Indeed, all synergies were observed to create life-cycle carbon savings that greatly outweigh the emissions created transporting the waste for reuse. Whilst for the suggestion that the value of a waste material did not obviously affect how far a material travelled for reuse, it was noted that the cost of waste disposal in the UK is so expensive that waste owners were justified in meeting the potentially expensive transport of many outwardly worthless materials to a location for reuse, near or far, rather than incur more expensive disposal costs or the cost of storing the waste to the required environmental standards. Despite being counterintuitive and opposed to general thinking on waste movement, the scenario where seemingly worthless materials can travel throughout the country was in fact observed on many occasions within the data Jensen et al. analysed. Thus, despite performing a variety of analyses on the NISP dataset, an obvious relationship between the intrinsic value of a waste material and how far it moved for reuse could not be found. Indeed, expanding on this observation, it could be argued that waste products do not adhere to normal resource movement drivers or restrictions; otherwise, when they are produced, they would appear within the 'shop window' of the waste producer and there would be no such concept of, or need for, industrial symbiosis or any other form of 'waste' management.

Instead, Jensen et al. (2011b) made an intuitive conclusion that resource movement must be dictated by the relative industrial diversity of the United Kingdom. That is to say, it was surmised that on average within a $32.6 \mathrm{~km}$ radius of a company within the United Kingdom, a business from a sufficiently unrelated industry will exist that is able to use the former company's 
by-products as a raw material within its own operations. The exception to this conclusion was that difficult to reuse materials, such as man-made composites, could be expected to travel further than 'everyday' common materials due to the need to find a symbiont company whose operations are specialised enough to be able to reuse the materials in question. Similarly to within biological ecosystems, resource specialists tend to be rarer and more restricted to the niches they can fill and proliferate within, than species that are classed as generalists. For instance, rats and cockroaches are geographically widespread due to their ability to survive in a multitude of habitats and on a variety of foodstuffs. Similarly, cement kilns, smelters and construction companies are relatively common and can use a large variety of both traditional and non-traditional raw materials in their everyday operations. However, specialist companies and their specialist operational resources are (by definition) rare in number and their geographic distribution.

Following the elimination of other potential restrictions to resource movement within industrial symbiosis agreements (as discussed above), the diversity focussed conclusions Jensen et al. (2011b) arrived at were largely formed on intuition. As such, in conjunction with an empirical analysis of the geospatial industrial diversity of England ${ }^{5}$, this paper seeks to test these conclusions by re-examining the synergy facilitation data produced and employed within the Jensen et al. (2011b) study. In performing the re-examination of Jensen et al. research conclusions, several propositions on what would be the expected effects of geospatial diversity on resource movement were derived for examination:

- Firstly, due to an increase in the number and type of waste reuse outlets, it was proposed that the more industrial diversity that exists around a company, the less distance their by-products would have to travel to a point of reuse by an unrelated symbiont company (or other organisation).

- Secondly, higher instances of localised 'species' richness would generate greater options for resource complementarity (as measured by high levels of different synergy types).

- Thirdly, areas of higher industrial diversity, in terms of population equitability, would allow synergy replication and thus promote higher instances of industrial symbiosis in general (as measured by local synergy numbers).

- Lastly, uncommon or 'specialist' materials will potentially move further, on average, to a point of reuse than 'everyday' general materials due to the rarity of potential symbiont companies that are capable of reusing specialist resources.

Herein this paper sets out to test these propositions ${ }^{6}$.

\footnotetext{
${ }^{5}$ Unlike the Jensen et al. (2011b) study that was conducted within England, Scotland and Wales, the symbiosesdiversity analyses presented here was solely performed within England due to changes to NISP funding and a consequent change in the availability of data since the Jensen et al. (2011b) study was performed. Where relevant, figures presented herein relating to the Jensen et al. (2011b) study have been corrected for the omission of data relating to NISP operations in Scotland and Wales.

${ }^{6}$ All propositions assume that symbiosis practitioners were aware of the general composition of the industrial districts that existed within (relative) close proximity of the companies they worked with. This assumption is derived from a
} 


\section{Industrial Diversity Mapping}

\subsection{Mapping the Geospatial Industrial Diversity of England}

What measures of diversity are employed with a given study - among the myriad quantitative and qualitative options available - is largely dictated by the specific research objective (or objectives) at hand. To address the propositions of this investigation, diversity will be considered in terms of species richness and also in terms of the evenness of population numbers sampled within each community.

To investigate the geospatial relationships between industrial diversity and industrial symbiosis, several GIS based analyses were conducted. The first analysis involved mapping the geospatial industrial diversity of England in respect of all companies within the country classified as a Small to Medium Enterprise (SME) or larger whose operations involve the use of raw materials and manufacture of physical products. The second analysis involved ascertaining the specific diversity that exists around each NISP member company, within England, involved in a synergy. The levels of industrial diversity surrounding each company were determined using a $5 \mathrm{x}$ $5 \mathrm{~km}$ data sampling square and using two further data sampling radii sizes equal to the average distance materials travel within NISP facilitated symbiotic agreements, and the unique distance each resource, from each Programme member company, travelled to its point of reuse.

The dataset of all English businesses employed to determine the geospatial industrial diversity of England was derived from a typical 'business-to business' marketing database where each company is categorised by, among other identifiers, Standard Industrial Classification (SIC) codes and company size (as measured by employee numbers) ${ }^{7}$. To avoid smaller enterprises such as 'high street' shops being included in the mapping of England's industrial diversity, all companies categorised as being smaller than SME were removed from the database ${ }^{8}$. Industries not normally characterised by the manufacture or use of physical products were also removed from the database (along with the head offices and non-production facilities of manufacturers). Finally, the edited database was disaggregated into separate datasets to represent 26 different types or 'species' of company (see Table 1). The final database employed to determine industrial diversity pertained to 67,706 unique companies that produce or manufacture physical products (the effects of the size of the dataset and its disaggregation into the 26 industrial 'species' are discussed later).

Following georeferencing of all companies manufacturing and production facilities, the edited datasets for each of the 26 'species' of company was imported into the ArcGIS 9.3 mapping environment and data points for all companies were plotted onto a boundary map of England. Different geographic data sampling grid sizes were trialled. Using 10 by $10 \mathrm{~km}$ and larger data sampling grids the resolution of the maps produced was observed to be too low to differentiate distinct geographic areas. Employing a 5 by $5 \mathrm{~km}$ grid system, however, proved to be a small enough sample size to provide suitable geographic definition within the final diversity map whilst still remaining large enough to provide a sufficient representation of the 'local'

\footnotetext{
working knowledge of NISP practitioners and their individual and collective knowledge base (see Jensen et al., 2011b; Lombardi and Laybourn, 2012 and Velenturf and Jensen, 2015).

${ }^{7}$ Such databases are available from any 'business-to-business' (B2B) marketing company or can be compiled, in the UK, from repositories of business information such as the Government's 'Companies House' (who act as a registrar for all UK based companies). The B2B dataset employed in this study was supplied by Capscan (see www.capscan.co.uk).

${ }^{8}$ Within the European Union an SME is a company who has at least ten (but less than 250 ) employees.
} 
diversity of a given area ${ }^{9}$. Once the data sampling size had been decided, the 5 by $5 \mathrm{~km}$ grid system was overlaid onto the boundary map of England and the company data points for each of the industry 'species' types.

Table 1: Summary of 2003 Standard Industrial Classification (SIC) industry types

\begin{tabular}{llc}
\hline SIC Section & Industry Description & $\%$ of Dataset \\
\hline A01.1 & Growing of Arable Products & $11.80 \%$ \\
A01.2 & Farming of Animals & $31.78 \%$ \\
A01.3 & Mixed Farming & $25.03 \%$ \\
CA & Mining of Energy Producing Materials & $0.20 \%$ \\
CB & Mining and Quarrying of Metals, Minerals and Chemicals & $0.19 \%$ \\
DA & Manufacture of Food Products and Beverages & $2.20 \%$ \\
DB & Manufacture of Textiles and Textile Products & $1.80 \%$ \\
DC & Manufacture of Leather and Leather Products & $0.24 \%$ \\
DD & Manufacture of Wood and Wood Products & $1.38 \%$ \\
DE & Manufacture of Paper and Paper Products & $5.13 \%$ \\
DF & Manufacture of Coke and Petroleum Products & $0.06 \%$ \\
DG & Manufacture of Chemicals & $1.82 \%$ \\
DH25.1 & Manufacture of Rubber Products & $0.27 \%$ \\
DH25.2 & Manufacture of Plastic Products & $1.25 \%$ \\
DI26.1,2,3 & Manufacture of Glass and Ceramics & $0.43 \%$ \\
DI26.4 & Manufacture of Bricks and Clay Products & $0.02 \%$ \\
DI26.5,6 & Manufacture of Cement, Lime and Plaster & $0.39 \%$ \\
DI26.7,8 & Manufacture of Stone Products & $0.28 \%$ \\
DJ27 & Manufacture and Forging of Metals & $0.76 \%$ \\
DJ28 & Fabrication of Metal Products & $4.58 \%$ \\
DK & Manufacture of Heavy Machinery & $4.10 \%$ \\
DL & Manufacture of Electrical Equipment & $3.73 \%$ \\
DM & Manufacture of Transport Equipment & $0.96 \%$ \\
DN36.1 & Manufacture of Furniture & $0.96 \%$ \\
DN37.2 & Recyclers of Non-Metal Wastes and Scrap & $0.04 \%$ \\
O90 & Sewage and Refuse Disposal and Sanitation & $0.62 \%$ \\
\hline & & \\
\hline
\end{tabular}

Note: Industry 'species' types were disaggregated into categories that, as far as possible, allowed distinct primary operational resource types to be grouped or, where appropriate, separated. See National Statistics (2002) for more details on the classification of industries via the SIC2003 system.

Using the ArcGIS 'Join-Relate' function, the data points for each of the 26 industry types were spatially assigned to the respective $5 \mathrm{~km}$ grid square which they fell within and duly recorded within the sampling grid's attribute table. Once the $5 \mathrm{~km}$ grid map layer's attribute table had been populated by all industry type data, the respective diversity of each square was calculated. To determine basic diversity (in terms of community evenness), the Simpson's index

\footnotetext{
${ }^{9}$ Once reaching a suitable level of map definition (i.e. 5 by $5 \mathrm{~km}$ ) experiments with smaller data sampling sizes ceased.
} 
of diversity $(D)$ was employed since it is one of the most widely employed, least sensitive to sample size and simpler to interpret of all of the measures of community diversity or, to be precise, measure of species sampling probability (see Eq. 1 and Simpson, 1949) ${ }^{10}$. The resulting values for $D$ fall within the range of 1 to 0 . After performing the calculation of $D$, each diversity index figure was subtracted from 1 (i.e. 1-D) to achieve an intuitive measure of diversity ranging from 0 (sample homogeneity) to 1.0 (high sample heterogeneity) ${ }^{11}$.

Eq. 1:

$D=\sum_{i=1}^{s R}\left(n_{i} / N\right)^{2}$

Note: where $s R$ is species richness, $n_{i}$ is the total number of individuals of each industrial 'species' type found within a given $5 \mathrm{~km}$ grid square, and $N$ is the total number of individuals of all 'species', or all companies, found within the same grid square.

Once 1- $D$ for each grid square had been calculated, the 5 by $5 \mathrm{~km}$ map grid was coloured on a sliding scale from low 1-D to high 1-D. To distinctly differentiate 'low' diversity geographic areas from 'higher' diversity geographic areas, the break values used to categorise 1-D data were set at the lower $50 \%$ of data values, upper $50 \%$ to $75 \%$ of values, upper $75 \%$ to $90 \%$ of values, $90 \%$ to $95 \%$ of $1-D$ values, and the top $5 \%$ of $1-D$ values. The NISP brokered synergy data employed within the Jensen et al. (2011b) study, following removal of all synergies facilitated within Scotland and Wales, was then superimposed onto the boundary map of England and the 5 $\mathrm{km}$ grid now representing the 1-D results. To explore the general relationships between geospatial industrial diversity and industrial symbiosis, statistics were generated for the number of synergies and the industrial diversity characteristics of the areas in which NISP facilitated synergies were brokered.

\subsection{Generating Diversity-Synergy Specific Data}

To explore the effects of geospatial diversity on the movement of specific resources involved in NISP brokered synergies, the specific level of diversity that existed around each resource donor company was determined. To perform this analysis, the $s R$ (species richness, i.e. distinct different forms of business) and 1-D figures of the $5 \mathrm{~km}$ grid square which the resource donor company fell within was assigned to the respective symbiont company's entry within the synergy dataset's GIS attribute table. This analysis was repeated by centrally positioning a circular data sampling plot, with a radius equal to the average distance resources move within England (i.e., $34 \mathrm{~km}^{12}$ ), around each resource donor company. For each sampling plot, species richness and the total number of all companies falling within it was recorded employing the same methods for spatially assigning industry types to a sampling area described for the $5 \mathrm{~km}$ grid

\footnotetext{
${ }^{10}$ See Magurran (2004) for an extensive appraisal of diversity indices and their appropriate application. Please also see note 15 regards to the issue of sample sizes and experiments with other common diversity indices.

${ }^{11}$ If grid square diversity figures are not subtracted by 1 , infinite diversity receives an unintuitive score of 0 and becomes a measure of a sampled community's population dominance, rather than a measure of population evenness.

${ }^{12}$ On removing resource movement data for Scotland and Wales from the synergy dataset the average distance materials moved increased from the $32.6 \mathrm{~km}$ reported by Jensen et al. (2011a) to $34 \mathrm{~km}$.
} 
sampling plot. To determine the extent of diversity which each resource encountered during their transport from their point of origin to their actual point of reuse, one further data sampling exercise was conducted. Unique sample plot sizes were created for each synergy corresponding to the specific distance their material had travelled to its point of reuse $\mathrm{e}^{13}$. Species richness and total companies falling within each synergy's unique sample plot was then recorded. For both circular data sampling plot sizes, 1- $D$ was calculated and attributed to each synergy's entry within the NISP synergy database. The NISP synergy database, now containing $S R$ and 1-D figures for the immediate area around each company (as determined using the $5 \mathrm{~km}$ grid square system), the area around each company up to the average distance resources move within symbiotic resource exchanges (i.e. $34 \mathrm{~km}$ ), and the specific distance each company's waste products actually moved, was exported to Microsoft Excel spreadsheet format to enable further analyses and interpretation of study results.

\section{Diversity-Symbiosis Analysis}

\subsection{Interpretation of Industrial Diversity Maps}

The geospatial industrial diversity of England is presented as per Figure 1. Firstly it can be seen that using a $5 \mathrm{~km}$ grid system as the scale for sampling the species richness and population data, and the use of 26 different industry types, allows good results in terms of visual resolution of geographic detail. Each of the known main industrial conurbations within England are represented by areas of relatively high industrial diversity and areas known to be characterised by agriculture, and even National Park areas, are clearly distinguishable within the map. This result was the culmination of a range of sensitivity analyses on data sampling grid sizes and the extent of industry type disaggregation applied to the company database to create different industrial 'species'. Such resolution of geographic detail could not be achieved when mapping the geospatial diversity of England at scales above $5 \mathrm{~km}$ or when using a smaller number of industry types to represent industry richness (maps for the results of the sensitivity analyses are not shown). Many uncertainties exist when sampling biological diversity in terms of determining whether every organism present has been identified and sampled. Knowing exactly how many 'species' exist with a study area and the exact size of each 'species' population perhaps highlights one area where industrial ecology can be more confident about its conclusions than is the case in orthodox ecology. The intuitively correct representation of the geospatial distribution and evenness of industrial facilities in England, shown in Figure 1, supports this argument.

\footnotetext{
${ }^{13}$ See Supplement, Fig. S.1a and S.1b for example images showing NISP member companies and their $34 \mathrm{~km}$ data sampling plots and unique data sampling plots.
} 


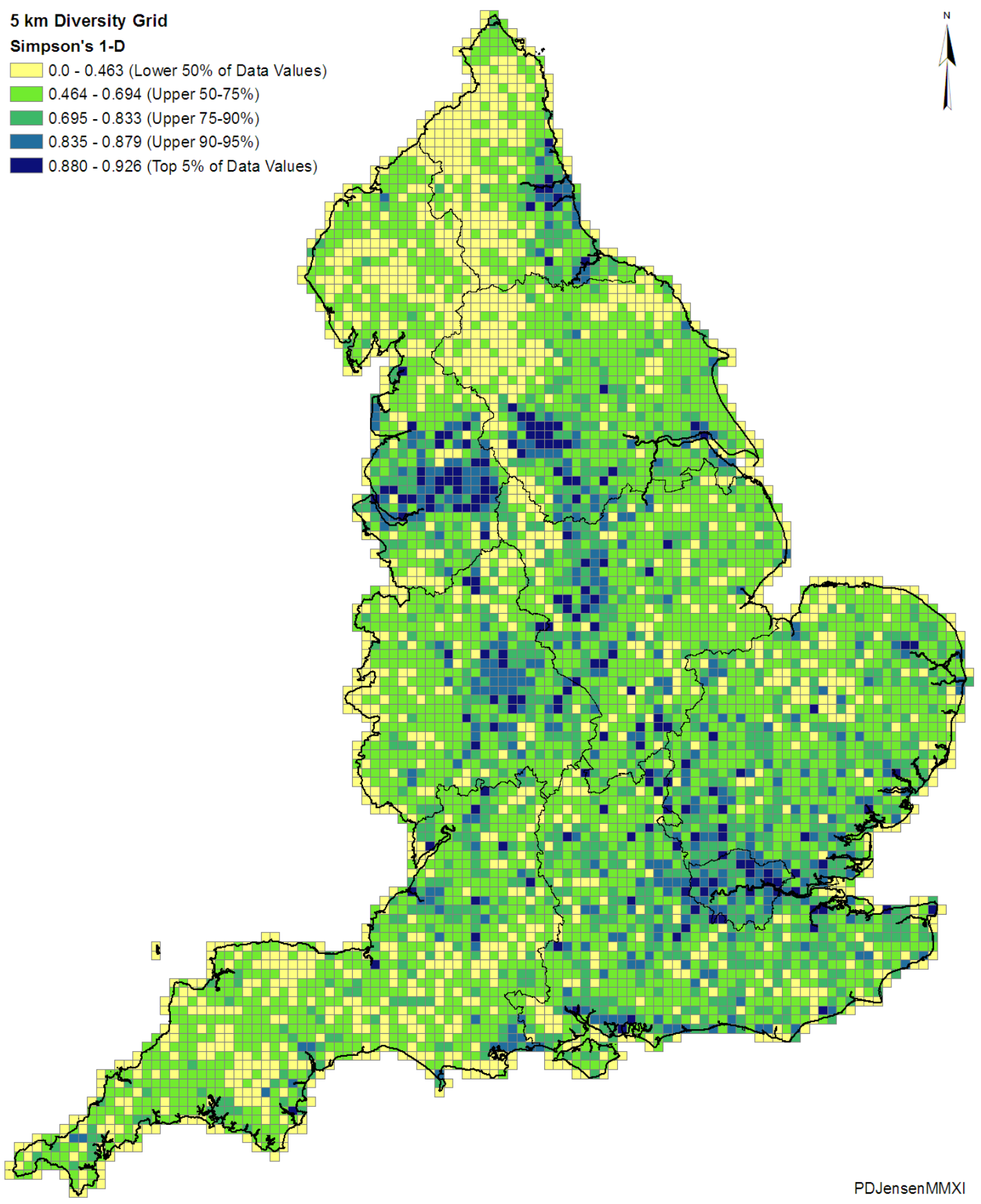

Figure 1: Industrial diversity $(1-D)$ of England using a 5 by $5 \mathrm{~km}$ data sampling grid Note: $D$ is the Simpson's diversity index of sample evenness

Figure 2 presents the map of England's geospatial industrial diversity of England plus the locations of NISP members involved in a synergy. The mapped results of Figure 2 present a good visual correlation between areas of high industrial diversity and the plotted resource movement networks of NISP member companies involved in synergies where materials moved within the average resource movement distance of $34 \mathrm{~km}$. Notably, Figure 2 also shows that companies who possessed or reused materials that travelled further than the average $34 \mathrm{~km}$ regularly lay within areas of lower geospatial diversity. These observations lend support to the research propositions of this study relating to high 'species' evenness and high levels of symbiosis and the distance materials have to travel to a point of reuse. 


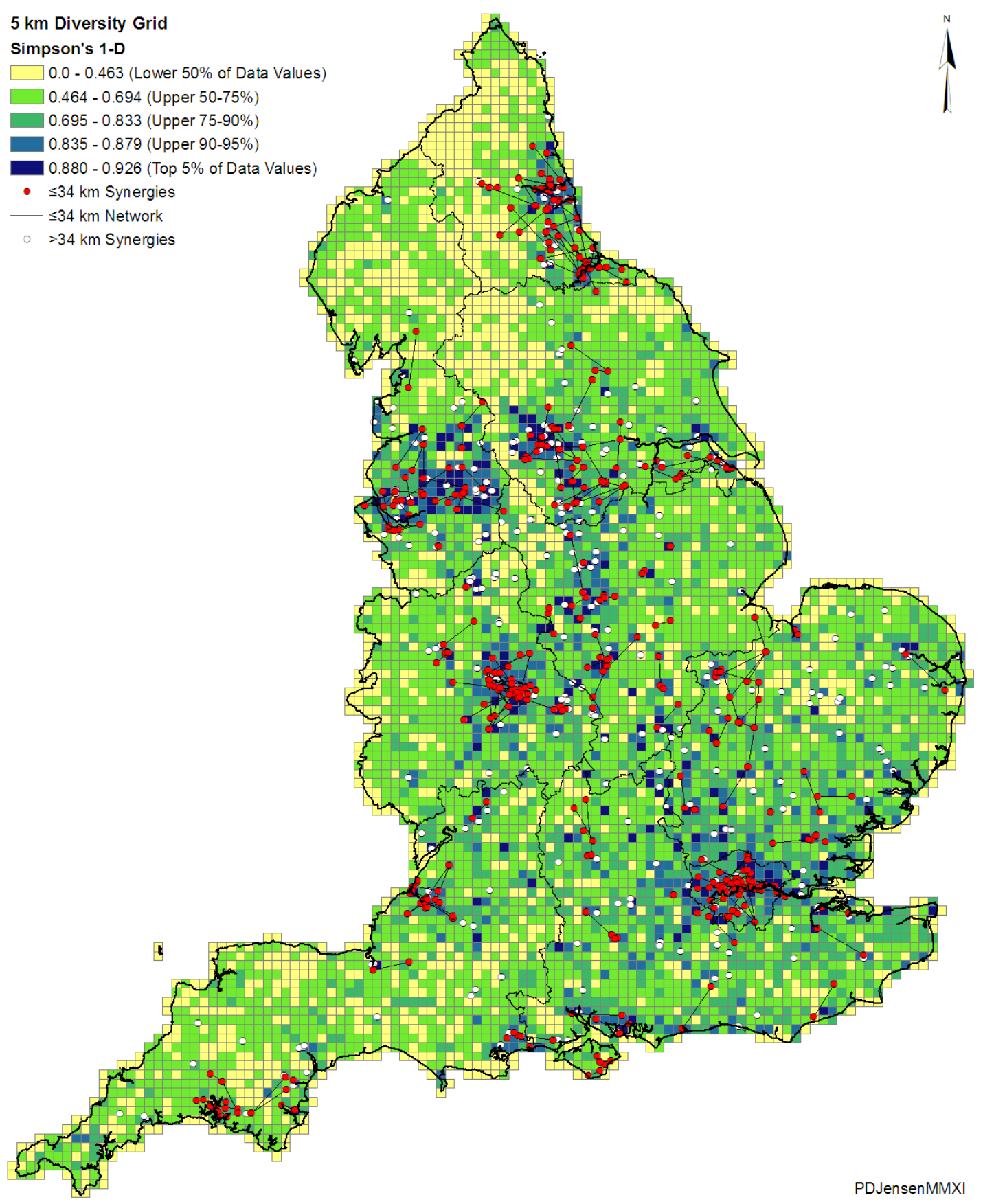

Figure 2: Industrial diversity (1-D) of England plus the NISP synergy network for materials moving within the average $34 \mathrm{~km}$ symbiotic resource movement distance and locations of companies involved in synergies where materials travelled further than $34 \mathrm{~km}$

Note: at the presented map scale it is difficult to differentiate between features, figure 2 is thus provided for information purposes only. To improve map feature clarity, the $>34 \mathrm{~km}$ synergy network is not shown. $D$ is the Simpson's index of sample evenness.

As is noticeable within Figure 1, many of the higher diversity areas are contiguous and diversity index values tend to increase and decline in gradients rather than extreme areas of high and low diversity being adjacent to each other. This is arguably a visual representation of the effects of economic agglomeration and lends some weight to the (cause-effect) suggestion that diversity, in terms of richness of 'species' begets, or promotes, diversity (i.e., niche construction/realisation). This observation is also consistent with observations within biological 
ecology as it resembles the composition of contiguous biological ecosystems where an intermediary transitional boundary, known as an ecotone, tends to exist. In considering the relationship between mapped industrial diversity and the analysed industrial symbiosis network, it was found that $76 \%$ of companies and their respective symbiont partner, who were involved in a synergy where the exchanged resource moved within the average resource movement distance of $34 \mathrm{~km}$, were both located within contiguous areas of diversity in the $90^{\text {th }}$ percentile of 1-D figures (i.e. $\geq 0.835$ ). When the same analysis was conducted using the entire synergy dataset (i.e. including the synergies where the given resource travelled further than $34 \mathrm{~km}$ ) this figure dropped to $63.1 \%$ : which still suggests that significantly more than half of the synergies occur in areas with the highest (i.e. top 10\%) levels of observed diversity as measured via Simpson's evenness index. These findings support the premise that areas of high 'diversity' (in terms of species evenness) will support higher overall numbers of (and opportunities for) industrial symbiosis.

\subsection{Interpretation of Synergy-Diversity Data}

In exploring the proposition that the by-products of companies situated in areas of high diversity would travel relatively short distances to find a suitably unrelated company able to reuse their waste materials, it is necessary to make the distinction between the two forms of diversity that have been measured within this study. Intuitively one could argue that localised basic species richness is a more suitable measurement for finding an area likely to contain a company from an unrelated industry than the 1-D measure (which provides a measure of community evenness in terms of population equitability). However, system-species evenness could also be desirable because it would be expected that over an extended period of time synergy replication would occur. Thus, locations with high 1-D would theoretically be areas where increased total opportunities for symbiosis would exist ${ }^{14}$. To explore the specific relationships that exist between species richness, community evenness and the distances materials moved within the dataset of analysed synergies, a frequency distribution for each parameter was produced using the symbiosis-diversity data generated for the $5 \mathrm{~km}$ grid based analysis and the two data sampling radii centred on each NISP symbiont company (Figure $3 \& 4$ ).

\footnotetext{
${ }^{14}$ When looking to replicate synergies, consideration would have to be given to whether evenness is measured in relation to a company's by-product production rate and the operational resource reuse capacity of a single potential symbiont, or in comparison to the cumulative resource reuse capacity of a collection of potential symbiont companies (and vice versa).
} 


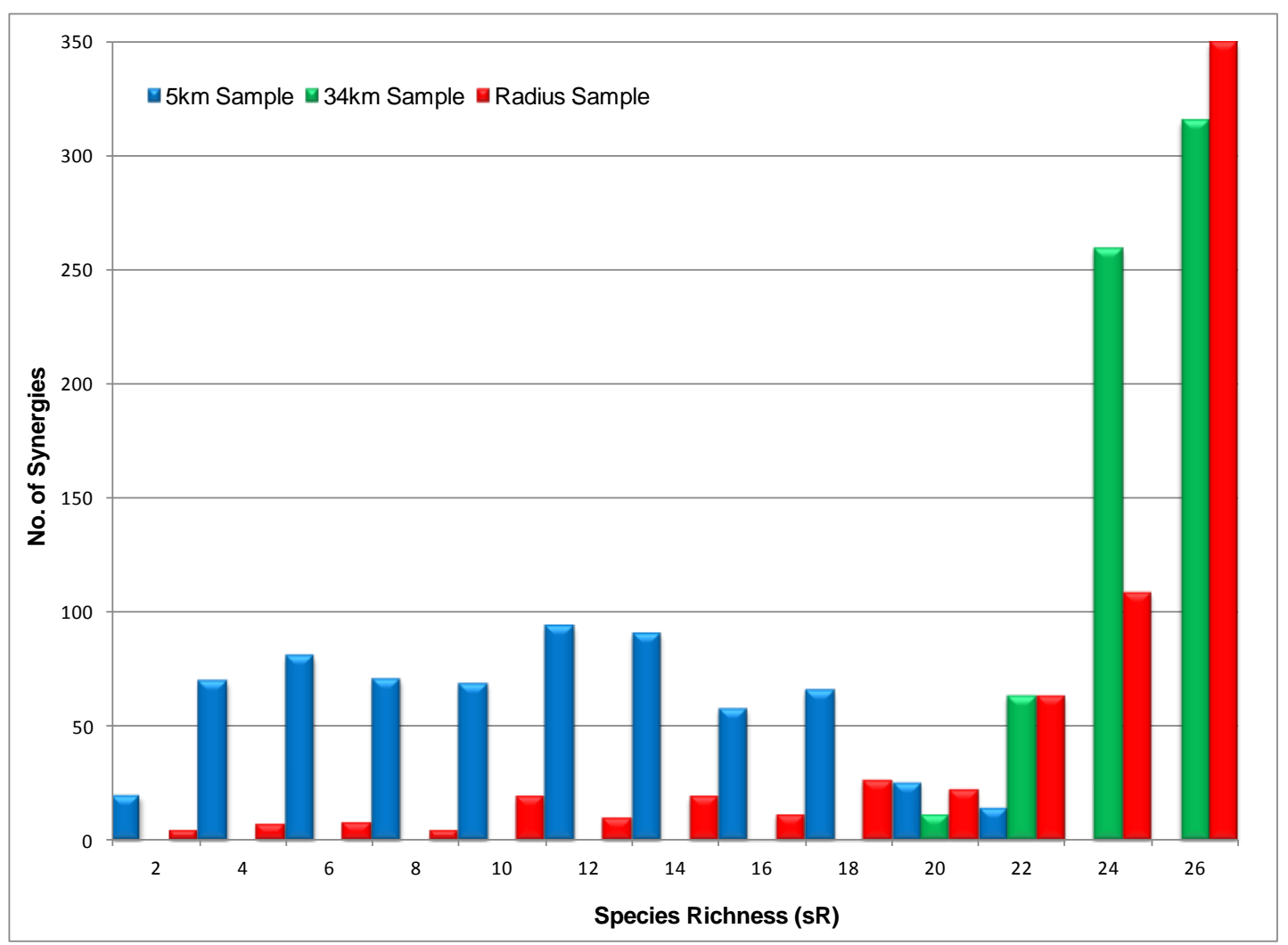

Figure 3: Frequency distribution of synergies in relation to species richness figures recorded for each of the $5 \mathrm{~km}, 34 \mathrm{~km}$ and resource movement radius data sampling plots

The multimodal distribution of the $5 \mathrm{~km}$ sample size bars displayed within Figure 3 indicates that, when no distinction is made between different industry types, there is no relationship between the species richness directly around a company and the number of synergies facilitated. It is notable that at the $5 \mathrm{~km}$ sampling scale, however, that very few companies have more than 20 different industry types within their direct proximity and none have more than 22 of the 26 industry types employed within the study. For the sample plot sizes corresponding to the specific distance each resource travelled (i.e. the 'radius' bars), it can be seen that there is, outwardly, a clear relationship between increasing species richness encountered and the number of synergies facilitated: at this data sampling scale, $80 \%$ of all companies resources encountered 22 or more different forms of industry before reaching their point of reuse. Notably, for the sample plot size corresponding to the average distance materials move within symbiosis agreements, species richness clearly increases markedly toward the known maximum number of industry types. Indeed, $98 \%$ of companies were found to have at least 22 different industries within their local proximity. This finding is particularly notable when it is highlighted that three of the 26 industry types each possess 'species' populations that represent $0.06 \%$ or less of the total of all companies present within the diversity dataset (see 'species' population figures within Table 1). If greater species richness is the key factor in local industrial symbiosis, this finding lends weight to the earlier Jensen et al. (2011b) assertion that a company from an unrelated industry, that is able to reuse the material of a donor company, should typically exist within the average resource movement distance of resource production origin (i.e. in England, $34 \mathrm{~km}$ ). 


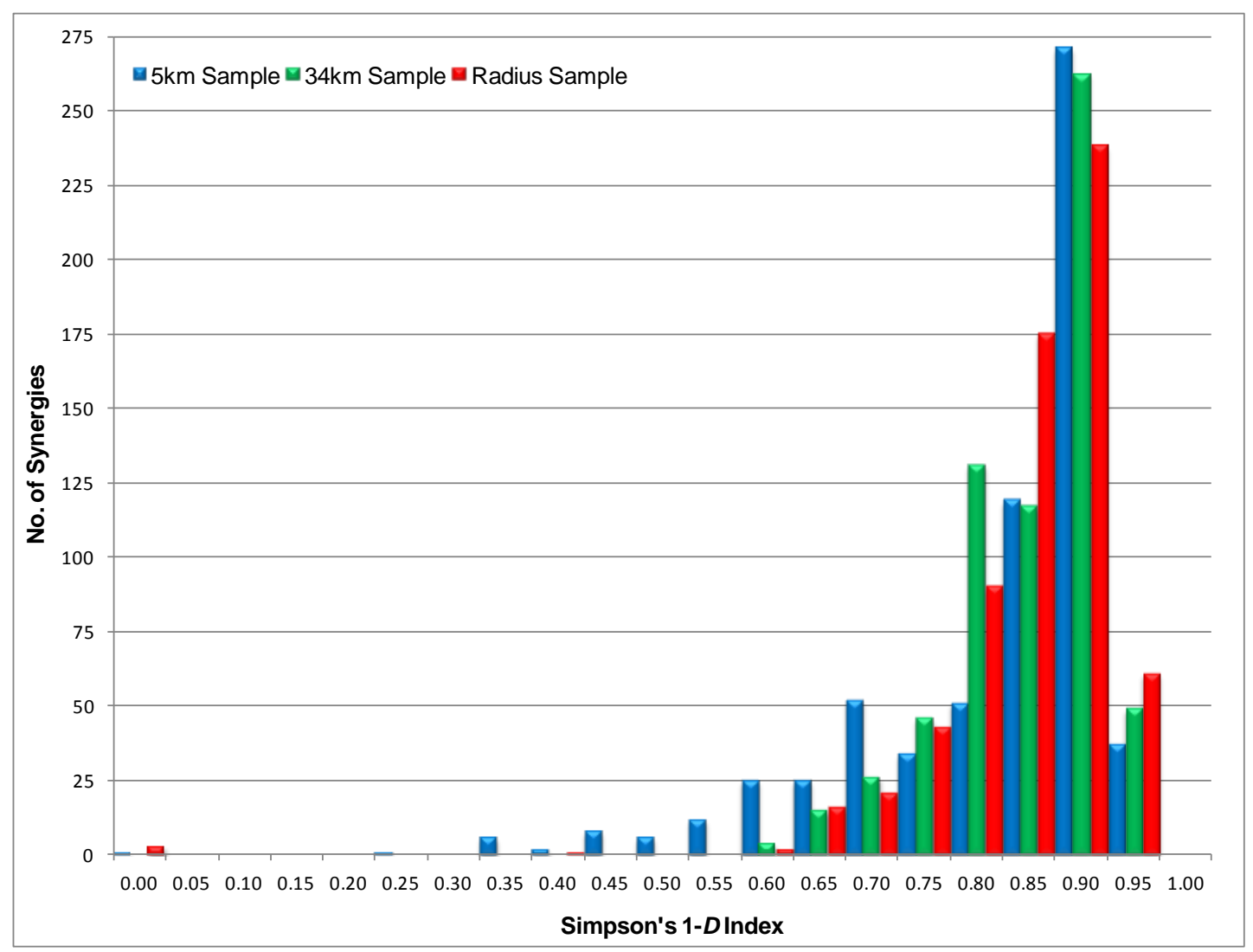

Figure 4: Frequency distribution of synergies in relation to 1-D figures recorded for the $5 \mathrm{~km}, 34$ $\mathrm{km}$ and resource movement radius data sampling plots

Interestingly, when the frequency distribution analysis was performed on the 1-D diversity evenness data recorded for each instance of symbiotic resource movement, the results provided a different 'story' to the synergy data recorded for species richness. Although the $34 \mathrm{~km}$ and resource movement radius sample plots produced 1- $D$ results similar to the species richness analysis, the results produced at the $5 \mathrm{~km}$ scale differed markedly. Whereas the richness analysis suggested that there was no obvious trend for companies involved in industrial symbiosis to be directly located within areas of high diversity (in terms of species richness), the 1- $D$ data suggests that when diversity is considered in relation to the evenness of a $5 \mathrm{~km}$ data sample square's industrial community, companies involved in industrial symbiosis do typically inhabit areas of high diversity. This finding highlights a potential flaw in the use of some of the popular evenness indices when they are employed to determine diversity within industrial ecology studies. Although the 1-D index allows good comparisons of diversity to be made between different samples due to its lack of sensitivity to sample scales, its inability to recognise the presence of rare species within a sample arguably reduces its effectiveness within industrial ecology research if richness is as important to promoting opportunities for industrial symbiosis as it appears to $b^{15}$. In terms of actively identifying opportunities for industrial symbiosis, however, these

\footnotetext{
${ }^{15}$ Notably, other indices were trialled during the symbiosis-diversity analysis which did give greater weighting to species richness. The popular Shannon index and Shannon Evenness indices were, in particular, both able to produce good results in terms of identifying rarer species but both proved to be extremely sensitive to sample sizes above the point where species richness started to reach saturation and thus were not deemed suitable for this particular study (or any diversity study where it is necessary to compare results from a multitude of different data sampling sizes). See
} 
collective findings could be useful. If diversity maps were produced at the preferred 5 by $5 \mathrm{~km}$ scale solely employing richness as the indicator of areas to start looking for opportunities for industrial symbiosis, Figure 3 richness-synergy frequency distribution suggests that such maps would not necessarily point a practitioner toward any areas of promise ${ }^{16}$. If, however, a practitioner used a 5 by $5 \mathrm{~km}$ 1-D diversity map (as per Figure 1 ) to identify areas where the best opportunities for localised industrial symbiosis exist, they would, based on the results of Figure 4, be more likely to achieve their objective. If a practitioner then performed a search around any company identified within high 1-D areas to a radius equal to a derived distance at which encountered species richness reaches saturation (i.e. in England, 24-26 species), a defined geographic area for actively identifying opportunities for 'local' industrial symbiosis would be identified $^{17}$.

\subsection{Interpretation of (Synergy) Distances-Diversity Data}

To determine the specific relationship between industrial diversity and the distance materials moved within the analysed NISP brokered synergies, further analyses were conducted into the actual distance at which species richness reached saturation and what effect this had on the number of synergy types facilitated (see Table 2). As the distances resources moved within the NISP synergy dataset possessed a non-normal distribution (i.e. skewness $=1.83$ ), the aggregated diversity data recorded within Table 3 was calculated using the interquartile mean to ensure production of robust statistics (i.e. ones not influenced by extreme outliers). In the first instance it can be seen that species richness starts to plateau in observed richness numbers and the range of richness numbers from the 30-35 km point onwards (i.e. 24 species types with an interquartile range, or data dispersion value, of 2 species). When it is recognised that three industry types within the industry dataset contained relative populations of $0.06 \%$ or less of the total dataset, and the maximum number of industry species types observable is 26 , this again adds weight to the claim that at approximately $34 \mathrm{~km}$ most businesses within England should be able to identify an unrelated symbiont company able to engage in symbiotic activities. As a further point of note, the $60-65 \mathrm{~km}$ distance category - where sampled species richness reaches its constant zenith (i.e. 26 species with a range of 0 ) - represents the upper quartile distance resources move within the NISP synergy dataset (i.e. $63.1 \mathrm{~km}$ ).

\footnotetext{
Supplement Figures S.2a, S.2b and S.2c for diagrams reflecting the comparative effect of different data sampling sizes on Simpson's 1-D and Shannon's Evenness indices

${ }^{16}$ This was found to be true regardless of what bin scale was used to produce the $5 \times 5 \mathrm{~km}$ richness-synergy frequency distribution (all bin scales produced a multimodal or 'messy' distribution). However, see Figure S.3 within the 'Diversity Analyses Supplement' for a $5 \times 5 \mathrm{~km}$ grid map of England that presents a good visual correlation between high densities of NISP synergies and high geospatial industrial richness.

${ }^{17}$ See Figure S.4 of the Supplementary Material for an example of the suggested methodology and the positive results of performing such an active symbiosis planning study.
} 
Table 2: Interquartile mean and interquartile range of species richness and 1-D figures for sample plots relating to resources moving up to $65 \mathrm{~km}$ (at $5 \mathrm{~km}$ binned intervals)

\begin{tabular}{ccccccc}
\hline Sample Plot Size & $\begin{array}{c}\text { Mean } \\
\text { sR }\end{array}$ & $\begin{array}{c}s R \\
\text { Range }\end{array}$ & $\begin{array}{c}\text { Mean } \\
1-D\end{array}$ & $\begin{array}{c}1-D \\
\text { Range }\end{array}$ & $\begin{array}{c}\text { No. of } \\
\text { Synergies }\end{array}$ & $\begin{array}{c}\text { No of } \\
\text { Synergy Types }\end{array}$ \\
\hline 0 to $5 \mathrm{~km}$ & 11 & 8 & 0.83 & 0.17 & 66 & $14(14)^{\mathrm{b}}$ \\
5.1 to $10 \mathrm{~km}$ & 18 & 9 & 0.85 & 0.11 & 60 & $15(16)$ \\
10.1 to $15 \mathrm{~km}$ & 22 & 3 & 0.88 & 0.07 & 43 & $12(18)$ \\
15.1 to $20 \mathrm{~km}$ & 23 & 5 & 0.86 & 0.07 & 59 & $15(18)$ \\
20.1 to $25 \mathrm{~km}$ & 24 & 3 & 0.86 & 0.10 & 39 & $11(18)$ \\
25.1 to $30 \mathrm{~km}$ & 24 & 2 & 0.87 & 0.06 & 28 & $13(19)$ \\
30.1 to $35 \mathrm{~km}$ & 24 & 2 & 0.83 & 0.09 & 46 & $13(19)$ \\
35.1 to $40 \mathrm{~km}$ & 25 & 1 & 0.86 & 0.07 & 48 & $13(19)$ \\
40.1 to $45 \mathrm{~km}$ & 25 & 0 & 0.84 & 0.10 & 26 & $10(19)$ \\
45.1 to $50 \mathrm{~km}$ & 26 & 1 & 0.81 & 0.10 & 25 & $8(19)$ \\
50.1 to $55 \mathrm{~km}$ & 26 & 1 & 0.81 & 0.08 & 18 & $10(19)$ \\
55.1 to $60 \mathrm{~km}$ & 26 & 1 & 0.80 & 0.08 & 19 & $9(19)$ \\
60.1 to $65 \mathrm{~km}$ & 26 & 0 & 0.85 & 0.02 & 12 & $7(19)$ \\
\hline All Synergies & 24 & 4 & 0.84 & 0.08 & $650^{\mathrm{a}}$ & 19 \\
\hline
\end{tabular}

Notes: ${ }^{\text {a }}$ The 650 synergies employed to conduct the analysis derived from the first batch of NISP synergies facilitated within England where reported outputs had been verified by a third-party auditor. Including Scotland, Wales and Northern Ireland, the actual figure for verified synergies was more than 1,200. When including synergies in the process of being facilitated or audited, this figure stood, by December 2011, at over $5,000{ }^{b}$ Figures given for synergy types are the number of different forms of synergy facilitated within the given sample plot size category. Figures given in brackets are cumulative synergy type figures (up to the maximum possible 19 physical resource synergy types).

As was earlier proposed, the cumulative number of different synergy types (categorised as indicated in Table 3 ) increases with the number of species encountered until reaching a point of saturation. This positive relationship (correlation $[r]=0.98$ ) again highlights the importance of the richness of industry types in promoting increased opportunities for symbiosis and increased local recycling and resource productivity. Interestingly, however, diversity in the form of 1-D community evenness seemingly has no relationship to the number of different synergy types facilitated $(r=-0.04)$. Although, when the relationship between 1- $D$ is again examined but only up to the point at which species richness begins to plateau (i.e. $30 \mathrm{~km}$ ), the relationship between 1-D and an increase in the number of local synergy types being facilitated increases significantly (i.e. $r$ $=0.87)$. It is assumed that this is because beyond the $30 \mathrm{~km}$ point, species richness increases slowly before stopping at $65 \mathrm{~km}$, whilst overall population numbers for better represented species inevitably continues to rise, thus producing lower 1-D figures the further you travel and consequently a reduced correlation to increasing synergy type figures. This is another notable issue with employing evenness focussed diversity indices in studies that cover large geographic scales (encompassing in this instance almost 68,000 industrial facilities) and once again emphasises that $s R$ (i.e., richness), as a minimum, must be ascertained and considered when performing diversity related research. To fully position the findings discussed here, sN (e.g., total numbers of businesses in a given area) was also assessed for its correlation to the analysed instances of NISP facilitated synergies. From a direct correlation of all data and also using a 
variety of frequency distributions, correlation figures ranging from -0.16 and -0.24 were produced. Given that one could justifiably suggest that higher numbers of industrial facilities would automatically equate to greater opportunities for symbiosis, the lack of a positive correlation between $s N$ and the instances of NISP facilitated symbiosis analysed here, is perhaps surprising. However, it could simply reflect, once again, the importance of industry type richness in addition to the total number of industries. Although a high number of businesses may be found in one area with consequent high flows of waste and by-products, if the industrial composition of the area is relatively homogenous it could be difficult to facilitate a local synergy due to the presence of a limited number and form of waste reuse outlets compared to an area rich in options for resource reuse. Although beyond the scope of this paper, further investigation is clearly required for a definitive conclusion to be drawn on the relationship (or lack of) between high $\mathrm{s} N$ and observed total numbers of NISP synergies.

In exploring the proposition that specialist resources would, on average, travel further to a point of reuse due to the need to encounter greater levels of species richness and, consequently, another specialist, an analysis of the relationship between resource movement and different resource streams was also conducted (data discussed below but not shown ${ }^{18}$ ). This analysis outwardly confirmed the proposition that specialist materials, such as man-made composites (e.g. inorganic chemicals, textiles, rubber), or generally difficult to reuse materials (e.g. sludges) travel further to a point of reuse than most other 'everyday' materials (e.g. paper, wood). Whether this observation was due to a lack of local diversity in the region of where the man-made composites were produced is, however, less clear. Due to the higher average distances each of the less common materials travelled (e.g. $144 \mathrm{~km}$ and $72 \mathrm{~km}$ for inorganic chemicals and rubber respectively), it is only to be expected that the recorded average richness figures for these specialist materials would be higher than the more general easier to reuse materials and the cumulative average for all resources. For example, in comparison to the mean richness for all resources being 24 with a data dispersion range of four, for both inorganic chemicals and rubber the mean richness recorded was 26 and both possessed a data range of one. The fact that the 1-D for these materials was lower than the average for all resources (i.e., 0.827 and 0.818 for rubber and inorganic chemicals respectively in comparison to an average for all materials of 0.842 ) does not refute the argument that specialist resources require higher levels of diversity to find a suitable resource reuse symbiont company. It simply highlights the facts that it is seemingly industry type richness which is most important to the likelihood of being able to facilitate a synergy, and 1- $D$ industry evenness figures are again being negatively affected by the fact that species richness starts to plateau at $30 \mathrm{~km}$ whilst species population numbers, based on relative population sizes shown in Table 1, increase disproportionately. Although several statistics of potential interest were produced when analysing the material specific relationships between industrial diversity and the facilitation of synergies, the relative uniformity of diversity figures which was produced at each resources specific movement radius sampling scale indicated that further bespoke analysis outside the scope of this more general study was required to fully uncover any notable trends.

\footnotetext{
${ }^{18}$ Given the discussed caveats to this particular analysis of the resource movement diversity data, the data table is not provided within the paper and are instead available for information purposes within the Supplementary Material, Table S.1.
} 
At the $5 \mathrm{~km}$ diversity sampling scale there was an apparent trend in relation to the levels of diversity that exist around different forms of industry: particularly in relation to what are deemed to be light and heavy industries and the level of ancillary industries they respectively attract to their locale. For instance, composts and soils regularly deriving from farms and horticultural businesses were found to lie, on average, in direct proximity of 6 different industries. Organic chemicals, meanwhile, typically deriving from heavy industries such as chemical processing where found to lie, on average, in direct proximity of 13 different industry types. Due to the large data dispersion ranges at the $5 \mathrm{~km}$ data sampling scale it is debatable, however, whether hard conclusions can be drawn on the scales of industrial diversity that typically surround companies from different industry types. For instance, again referring to the organic chemicals synergy type, its species richness data dispersion range was 11 . Moreover, the article authors' knowledge of early NISP resource cataloguing methods would suggest that some of the analysed resource types do not necessarily derive from the industries one would intuitively expect (e.g. most industries produce paper and cardboard waste). As such, it is not easy to confirm which industries individual resources streams handled by NISP (ranging from paper and cardboard through to textiles, rubber and inorganic chemicals) came from. Consequently, it is advisable to consider these highlighted issues when attempting to determine any industry specific relationships between geospatial industrial diversity and the known instances of industrial symbiosis employed within this study. The specific task of determining material and industry specific relationships between geospatial industrial diversity and opportunities for local industrial symbiosis clearly requires further data gathering, categorisation, and context-specific analysis before sound conclusions can be derived. However, this caveat to the material specific analysis should not detract from the earlier conclusions drawn on the general movement of byproducts and wastes which remain robust.

\subsection{Summary of symbiosis-Diversity Relationship}

In summary, revisiting the propositions discussed in Section 3, it appears that local richness of industry types is the primary driver behind the distances materials travel from their point of origin to a point of reuse by a company from an unrelated industry. Furthermore, the argument that the average $34 \mathrm{~km}$ distance materials move within brokered symbiotic agreements is dictated by the relative geospatial diversity of England, has been shown to be valid. Likewise, the proposition that high instances of local industry richness would be areas possessing higher instances of differing synergy types was also shown to be correct. In general, areas of higher diversity, whether measured by industry type richness or relative community evenness, do possess greater instances of companies involved in local industrial symbiosis. By definition, these areas of high industrial symbiosis also possess higher rates of localised resource recycling and reuse and thus system productivity ${ }^{19}$. Although there is both intuitive and cursory statistical evidence to support the assumption that specialist resources do indeed have to travel longer distances - on average - to find a similarly specialist prospective symbiont partner, further research is required before a robust conclusion can be drawn on this subject. In terms of synergy

\footnotetext{
${ }^{19}$ Increased system "production" is not the same as increased "productive efficiency". In simple terms, production is a measure of how much 'biomass' a given system produces, whereas productive efficiency is a measure of how much a system produces in relation to how much it uses (usually measured in terms of the ratio of usable energy return over usable energy input).
} 
replication, community evenness is patently important but the measurement and classification of evenness needs more development for it to be a meaningful term or measure of diversity within industrial systems. Indeed, without robust diversity indices that are able to incorporate an appreciation of the number and/or type of functional and redundant roles a given 'species' plays within an ecosystem, the measure of diversity employed must recognise all species equally. Otherwise, an area that contained a single individual of a species that acts as a 'keystone' organism, able in this case to act as a hub of high symbiotic activity, such as a large chemical company with its diverse resource demands and outputs, could be wrongly overlooked if the sample also contained large populations of one or more other species. The potential for such areas to be dismissed as a site of interest due to its relative homogeneity highlights a significant drawback to employing common population evenness indices in regional symbiosis research and, eventually, proactive symbiosis planning.

Neither the productive efficiency nor resilience (apart from anecdotal observations) of the mapped areas of higher industrial diversity was examined in detail; thus, no firm conclusion can be drawn on the wider effects of geospatial diversity on these much debated aspects of ecosystem functioning. Resilience and productive efficiency, along with the need for testing and development of additional measures of diversity, are areas for essential further industrial diversity research.

\section{Development of Diversity Mapping and Conclusions}

\subsection{Potential Development and Application of Diversity Maps}

In conducting the presented study into industrial diversity and industrial symbiosis, several areas for further research have become apparent, whilst numerous options for improving the diversity analysis and mapping methodologies have also been identified. The first more obvious area for development would involve industry specific analysis of the effects of industrial diversity on opportunities for resource efficiency, and the specific effects of diversity on the development of to be identified industrial community diversity typologies ${ }^{20}$ (if such typologies exist).

In addressing the limitations of 1-D as a measure of diversity within industrial ecology research it would be beneficial to explore more indices which recognise the presence of rare species types within a data sample. Indices which are more sensitive to rare species types, but, unlike the obvious choice of Shannon and Shannon Evenness indices, are not affected by the varying and extremely large sampling scales employed to conduct elements of this study, would be of particular interest. In relation to the previously discussed importance of distinguishing between functional and redundant species within ecosystems, and their respective influence on a given system, it would be beneficial to recreate many of the presented analyses using the rising number of functional diversity indices and the increasingly sophisticated ways they are employed (e.g. Mouchet et al., 2010). By exploring the earlier statement that 'not all species are equal', by ascertaining the fundamental resource usage niches that each industry can fill( by cataloguing all known and theoretical forms of industrial symbiosis a given industry can be involved in), it would be possible to generate a niche based diversity index that, once mapped using the methods

\footnotetext{
${ }^{20}$ Beyond those industrial typologies already described within the economic geography literature and industrial agglomeration research.
} 
presented within this article, would be expected to be able to allow (forward and retrospective) context-sensitive regional resource efficiency planning to be performed.

In addressing the point that $\mathrm{s} R$, or richness, currently seems to be the best indicator of areas suited to industrial symbiosis, should more industry 'species' types be derived and included in further analysis of the relationship between industrial diversity and the movement of resources within synergies? Sensitivity analyses performed during this study suggested that the more industry types employed, the better the resolution of the diversity maps. If diversity begets (relative) diversity, how many more industries do this study's 26 industry types beget? Can methods be developed (or already exist) for estimating the diversity of geographically proximate ancillary industries a particular industry attracts? Can more (or more contextually appropriate) industry type resolution be drawn out of the 26 categories of industry employed in this study or any further similar studies?

Finally, based on largely anecdotal knowledge of many of the areas identified in Figure 1 as being high in industrial diversity, doubts could be raised about the relationship of diversity to ecological resilience as many of the areas are, currently, known to possess notable levels of industrial dereliction and redundancy (in terms of infrastructure and levels of unemployment). Examining this potentially significant and important observation further would require extensive contextual research. Such research was beyond the scope of the presented study but would be of considerable value to researchers seeking to understand the temporal dynamics of industrial ecosystem functioning and stability.

\section{$\underline{6.2 \text { Outlook \& Conclusions }}$}

Importantly, in this study existing industry was analysed in conjunction with real instances of industrial symbiosis. The study was not built on theoretical assumption or idealisms which are (understandably) commonplace within industrial ecology research. Regardless of the results of this study showing that localised diversity within industrial ecosystems does indeed promote resource reuse, recycling and, potentially, increased system production, an overriding conclusion of this study could be to not recommend the artificial introduction or promotion of industry diversity. As with biological ecosystems, interfering with the self-organised composition of a given area, without sufficient forethought of the consequences of any proposed changes, could prove to be disastrous in terms of maintaining or promoting existing aspects of diversity which industrial ecologists perceive to be important in promoting sustainable industrial development. For example, if one or more existing businesses who currently have key roles in resource efficiency and/or wider system resilience in a given area are 'outcompeted' by a newcomer, their distinct function within the system could potentially be lost. Allowing diversity to develop naturally within industrial ecosystems, before looking to apply intelligence-based thinking to efforts to exploit the inevitable opportunities for resource efficiency that will intrinsically exist within 'organically' diverse areas, would perhaps be the better option in areas where diligent industrial ecosystem planning cannot be exercised. Niche theory helps us to understand how diversity evolves and how opportunities for resource complementarity will inevitably arise. Through diversity mapping and similar studies, and the essential development of industrial niche, keystone and function based indices, we can readily identify areas of high industrial diversity and look to deploy experienced symbiosis practitioners to these areas to identify opportunities for context-appropriate industrial symbiosis. 
In conclusion, it is acknowledged that there is extensive debate on the subject of diversity and its effects on system functioning and the subject of how diversity is or should be measured. Diversity is a veritable minefield of a subject; hence for this study, which in many ways is the first of its kind in the context of industrial ecology and the use of extensive empirical industrial symbiosis data, a conscious effort was made to keep each analysis as straight forward and simple as possible. There is significant room for improvement within the field of industrial ecology when it comes to performing essential context-sensitive research of all aspects of industrial ecosystem evolution and functioning. It is hoped that this paper can provide a platform for discussion and further and more detailed empirical studies into the role geospatial industrial diversity plays in the functioning of industrial ecosystems.

\section{Acknowledgments}

This paper forms one element of research conducted into regional resource planning by Paul D. Jensen. The Regional Resource Planning project was financially supported by the United Kingdom's Engineering and Physical Sciences Research Council (EPSRC) and International Synergies Ltd (architects and deliverer of the National Industrial Symbiosis Programme). The author would like to thank NISP's Helen Hitchman for her advice on the development of the methods employed in the paper and her expert opinion on the findings of the research. Many thanks are also offered to NISP's Adrian Murphy and the University of Surrey's Lauren Basson, Matthew Leach, Alexandra Penn, Anne P.M. Velenturf and the three anonymous reviewers for their comments and constructive feedback which greatly improved this and earlier versions of the paper.

\section{References}

Ashton WS. The structure, function and evolution of a regional industrial ecosystem. Journal of Industrial Ecology 2009; 13(2): 228-246.

Begon M, Townsend CR, Harper JL. Ecology: from individuals to ecosystems, 4th ed. Oxford (UK): Blackwell Publishing; 2006.

Belussi F, Caldari K. At the origin of the industrial district: Alfred Marshall and the Cambridge school. Cambridge Journal of Economics 2009; 33(2): 335-355.

Chertow MR. Industrial symbiosis: literature and taxonomy. Annual Review of Energy and Environment 2000; 25: 313-337.

Chertow MR. "Uncovering” industrial symbiosis. Journal of Industrial Ecology 2007; 11(1): 11-30.

Costa I, Ferrão P. A case study of industrial symbiosis development using a middle out approach. Journal of Cleaner Production 2010; 18(10-11): 984-992. 
Côté RP, Smolenaars T. Supporting pillars for industrial ecosystems. Journal of Cleaner Production 1997; 5(1-2): 67-74.

Flombaum P, Sala OE. Higher effect of plant species diversity on productivity in natural than artificial systems. Proceedings of the National Academy of Sciences 2008; 105(16): 60876090.

Gibbs D. Industrial symbiosis and eco-industrial development: an Introduction. Geography Compass 2008; 2(4): 1138-1154.

Hardy C, Graedel TE. Industrial ecosystems as food webs. Journal of Industrial Ecology 2002; 6(1): 29-38.

Hooper DU, Chapin III FS, Ewel JJ, Hector A, Inchausti P, Lavorel S, Lawton JH, Lodge DM, Loreau M, Naeem S, Schmid B, Setala H, Symstad AJ, Vandermeer J, Wardle DA. Effects of biodiversity on ecosystem functioning: a consensus of current knowledge. Ecological Monographs 2005; 75(1): 3-35.

Hurlbert SH. The nonconcept of species diversity: a critique of alternative parameters. Ecology 1971; 52(4): 577-586.

Jensen PD, Basson L, Leach M. Reinterpreting industrial ecology. Journal of Industrial Ecology 2011a; 15(5): 680-692.

Jensen PD, Basson L, Hellawell EE, Bailey MR, Leach M. Quantifying 'geographic proximity': experiences from the United Kingdom's National Industrial Symbiosis Programme. Resources, Conservation and Recycling 2011b; 55(7): 703-712.

Jost L. Entropy and diversity. Oikos 2006; 113(2): 363-375.

Korhonen J. Four ecosystem principles for an industrial ecosystem. Journal of Cleaner Production 2001; 9(3): 253-259.

Korhonen J. Theory of industrial ecology: the case of the concept of diversity. Progress in Industrial Ecology 2005; 2(1): 35-72.

Korhonen J, Snäkin J-P. Analysing the evolution of industrial ecosystems: concepts and application. Ecological Economics 2005; 52(2): 169-186.

Laybourn P, Morrissey M. NISP: pathway to a low carbon economy. Birmingham (UK): International Synergies Ltd; 2009.

Lombardi DR, Laybourn P. Redefining industrial symbiosis: crossing academic practitioner boundaries. Journal of Industrial ecology 2012; 16(1): 28-37. 
Liwarska-Bizukojc E, Bizukojc M, Marcinkowski A, Doniec A. The conceptual model of an ecoindustrial park based upon ecological relationships. Journal of Cleaner Production 2009; 17(8): 732-741.

Loreau M. Biodiversity and ecosystem Functioning: recent theoretical advances. Oikos 2000; 91(1): 3-17.

Magurran AE. Measuring biological diversity, Oxford (UK): Blackwell Publishing; 2004.

Mayer AL. Ecologically-based approaches to evaluate the sustainability of industrial systems. International Journal of Sustainable Society 2008; 1(2): 117-133.

Mirata M. Experiences from early stages of a national industrial symbiosis programme in the UK: determinants and coordination challenges. Journal of Cleaner Production 2004; 12(8-10): 967-983.

Mouchet MA, Villéger S, Mason NWH, Mouillot D. Functional diversity measures: an overview of their redundancy and their ability to discriminate community assembly rules. Functional Ecology 2010; 24(4): 867-876.

National Statistics. UK standard industrial classification of economic activities 2003. London (UK): The Stationary Office; 2002.

Nielsen SN. What has modern ecosystem theory to offer cleaner production, industrial ecology and society? The views of an ecologist. Journal of Cleaner Production 2007; 15(17): 16391653.

Nielsen SN, Müller F. Understanding the functional principles of nature-proposing another type of ecosystem services. Ecological Monitoring 2009; 220: 1913-1925.

Odum EP. The strategy of ecosystem development. Science 1969; 164(3877): 262-270.

Renner GT. Geography of industrial localization. Economic Geography 1947; 23(3): 167-189.

Simpson EH. Measurement of diversity. Nature 1949; 163(4148): 688.

Tilman D, Reich PB, Knops J, Wedin D, Mielke T, Lehman C. Diversity and productivity in a longterm grassland experiment. Science 2001; 294(5543): 843-845.

Velenturf APM, Jensen P. Promoting Industrial Symbiosis: Using the Concept of Proximity to Explore Social Network Development. Journal of Industrial Ecology 2015; In Press.

Wells PE, Darby L. Re-writing the ecological metaphor, part 2: the example of diversity. Progress in Industrial Ecology 2006; 3(1-2): 129-147. 
Wright RA, Côté RP, Duffy J, Brazner J. Diversity and connectance in an industrial context: the case of Burnside industrial park. Journal of Industrial Ecology 2009; 13(4): 551-564.

Yachi S, Loreau M. Biodiversity and ecosystem productivity in a fluctuating environment: the insurance hypothesis. Proceedings of the National Academies of Science 1999; 96(4): 1463-1468.

Yue TX, Liu JY, Li ZQ, Chen SQ, Maa SN, Tian YZ, Ge F. Considerable effects of diversity indices and spatial scales on conclusions relating to ecological diversity. Ecological Modelling 2005; 188(2-4): 418-431. 
The Role of Geospatial Industrial Diversity in the

Facilitation of Regional Industrial Symbiosis:

SUPPLEMENTARY INFORMATION

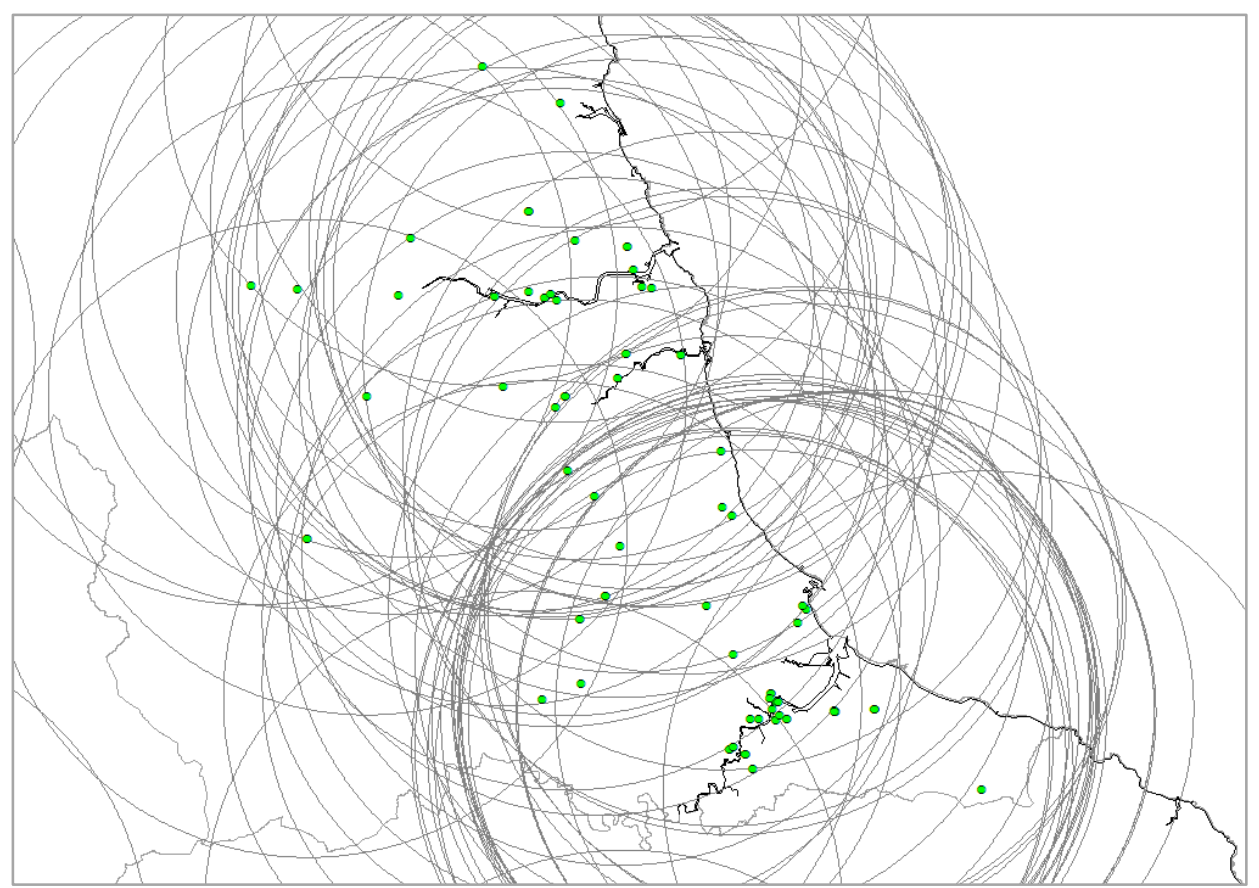

Figure S.1a: Example of NISP member companies (green dots) within the north-east of England and their respective $34 \mathrm{~km}$ diversity data sampling plots

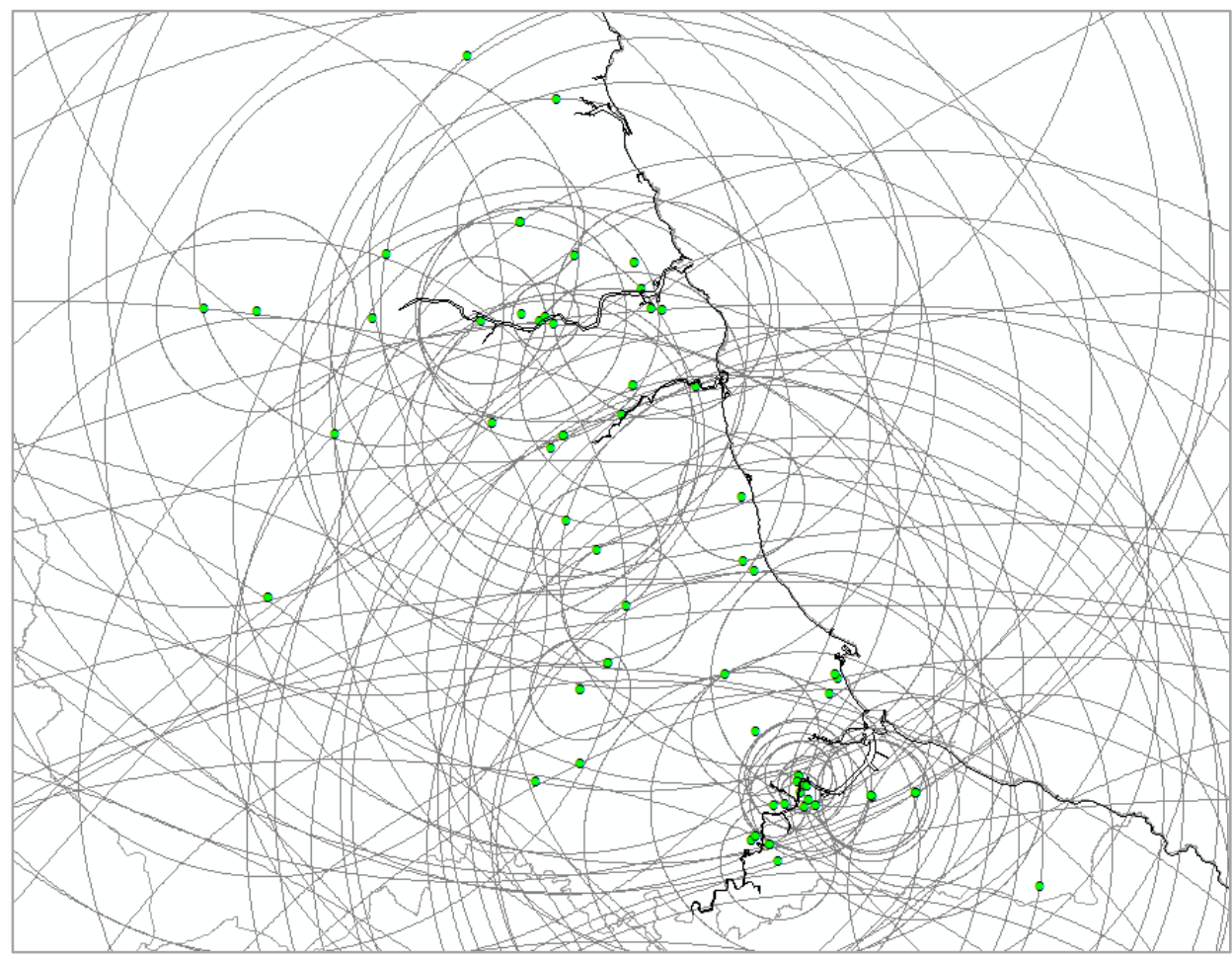

Figure S.1b: Example of NISP member companies (green dots) within the north-east of England and their diversity data sampling plots equal in size to the distance their respective resources travelled to a point of reuse 


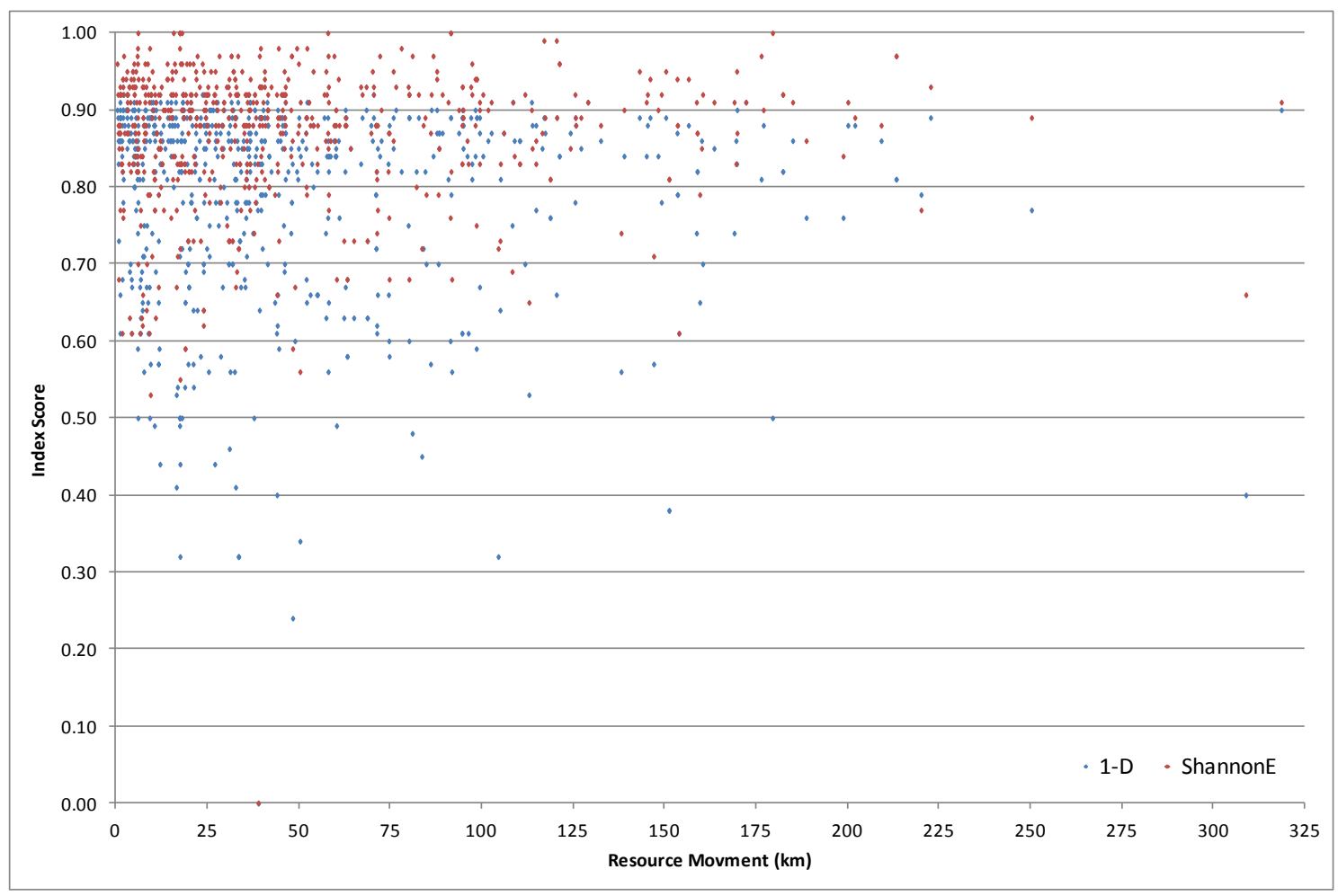

Figure S.2a: Simpson's 1- $D$ vs. Shannon's Evenness diversity index (5 km synergy sample grid)

Note: when considered together, Figures S.2a, S.2b and S.2c show the influence of increasing geographic diversity data sampling scales on the Shannon's Evenness (ShannonE) index in relation to the Simpson's (1-D) diversity index. Unlike the Simpson's index which is entirely weighted toward the evenness of the populations of each sampled species, the ShannonE index is weighted toward the presence of rare species. Consequently, as the sampling area increases ShannonE index figures reduce as the total population of sampled industry types rise disproportionately to the richness of industry types encountered (26 industry types were employed within the presented industrial diversity research, whilst the number of all companies analysed totalled 67,706). Sensitivity to sample size is particularly noticeable for the ShannonE index at the variable scales employed to represent data sampling plots equal in size to the distance each resource moved from the location of a NSIP member company, to its point of reuse (see Figure S.2C). Not being able to make like-for-like comparisons between the different data sampling sizes of each synergy, did not lend the ShannonE index to the objectives of the presented regional resource planning research. It is acknowledged, however, that the ability to identify rare industries within a data sample could make the ShannonE index potentially useful within further regional resource planning diversity studies. 


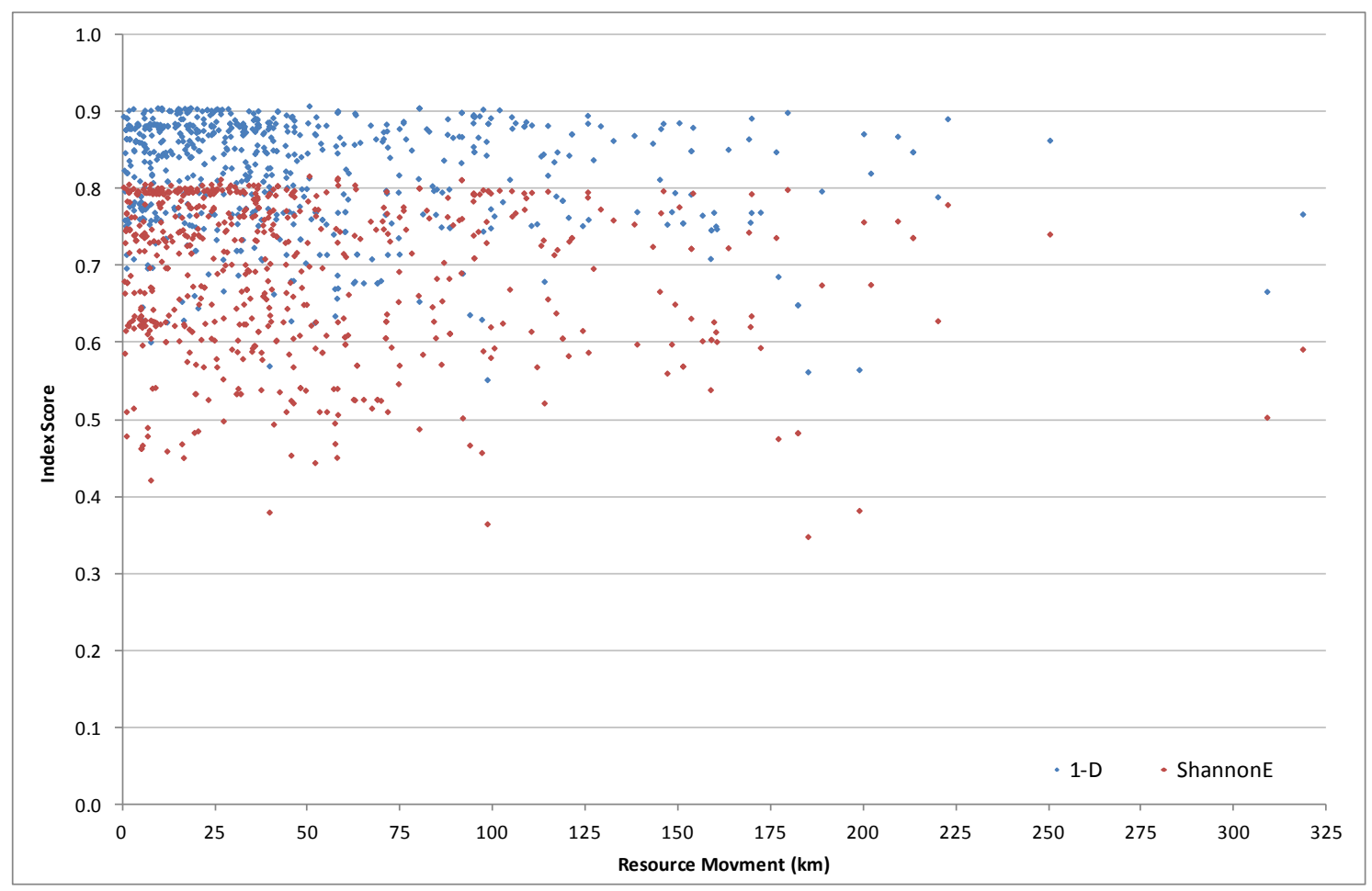

Figure S.2b: Simpson's 1-D vs. Shannon's Evenness diversity index (34 km synergy sample radius)

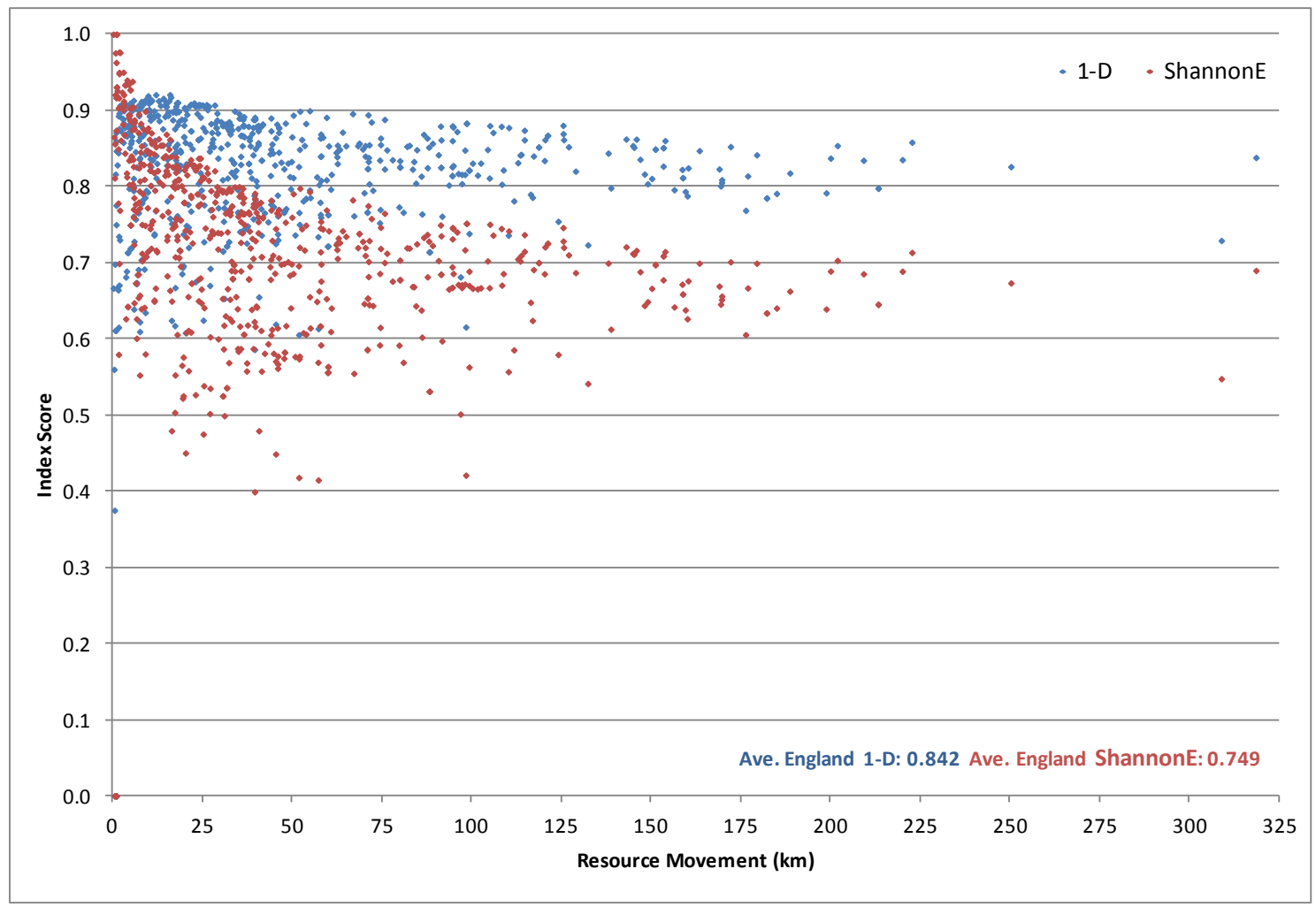

Figure S.2c: Simpson's 1-D vs. Shannon's Evenness diversity index (data sampling radius equal to the distance each resource, from each resource donor company, travelled to its point of reuse) 


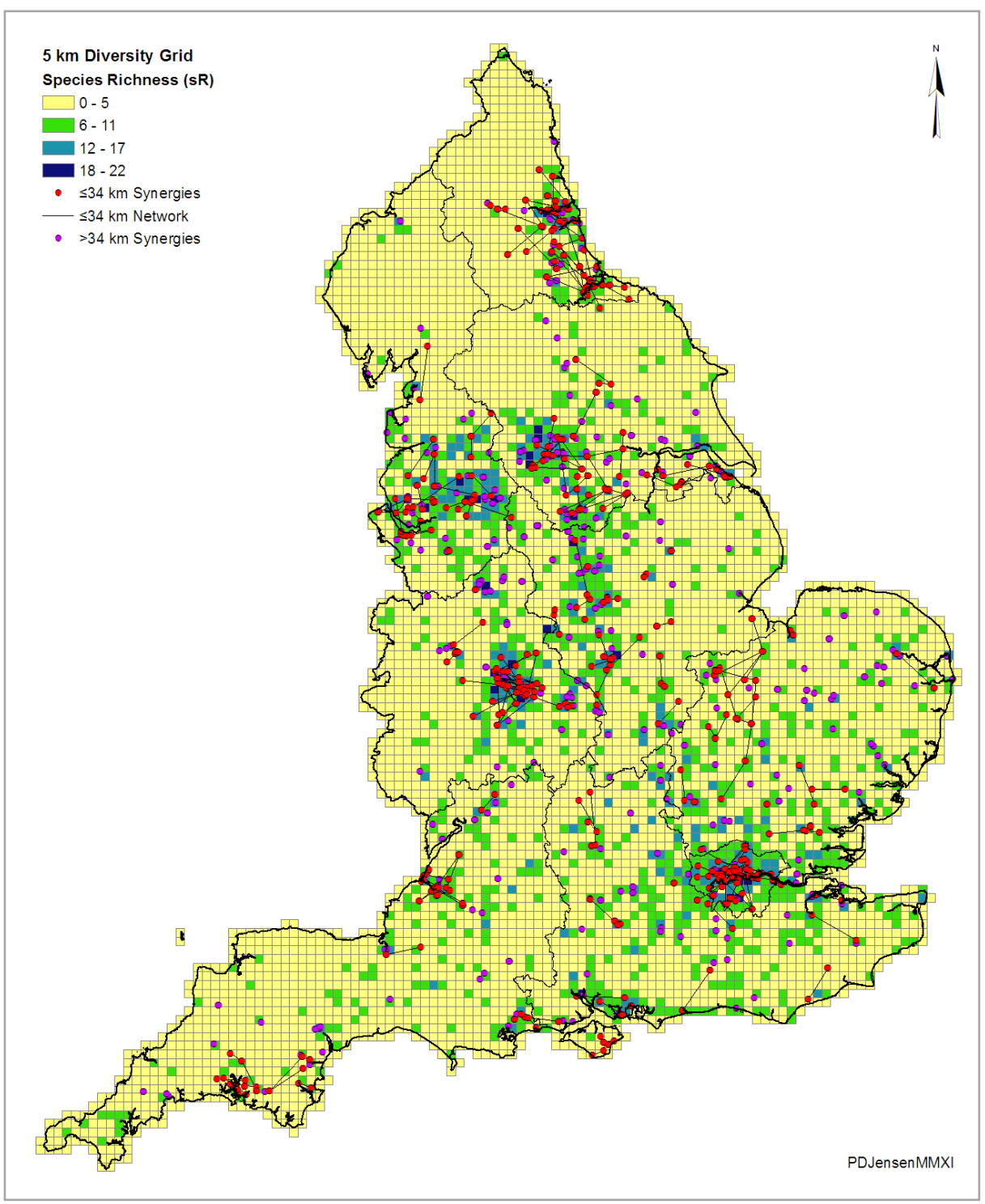

Figure S.3: Industrial diversity (industry richness) and NISP symbioses network

Note: it can be seen that the map of industrial richness correlates well to the NISP network of material based synergies. It is noticeable that companies whose resources travelled further than the average $34 \mathrm{~km}$ within England (violet dots [route network not show to maintain map clarity]) are, in comparison to companies whose resources travelled within the $34 \mathrm{~km}$ average (red dots), regularly located in areas of lower industrial richness. In contrast to the results of the frequency distribution presented within the main text of this paper, there is an obvious relationship between high richness at the $5 \mathrm{~km}$ data sampling scale and known instances of local symbioses. This highlights that industrial ecology diversity studies that are not considered in a contextspecific manner (i.e. in this case, the geospatial relationship between diversity and resource movement) can easily generate misleading results. This anomaly is created by the fact that diversity begets local diversity and resources are primarily moving within these contiguous areas of high industrial richness. It is hard to appreciate this particular synergy-richness relationship within a frequency distribution. Compared to Figure 1 shown within this paper's main text, it is noticeable, however, that a map of geospatial industrial richness does not present a depiction of the country that is as geographically representative (or true to life) of England as the map's created using Simpson's 1-D index (i.e., Figure 1 within the main text of this paper). 


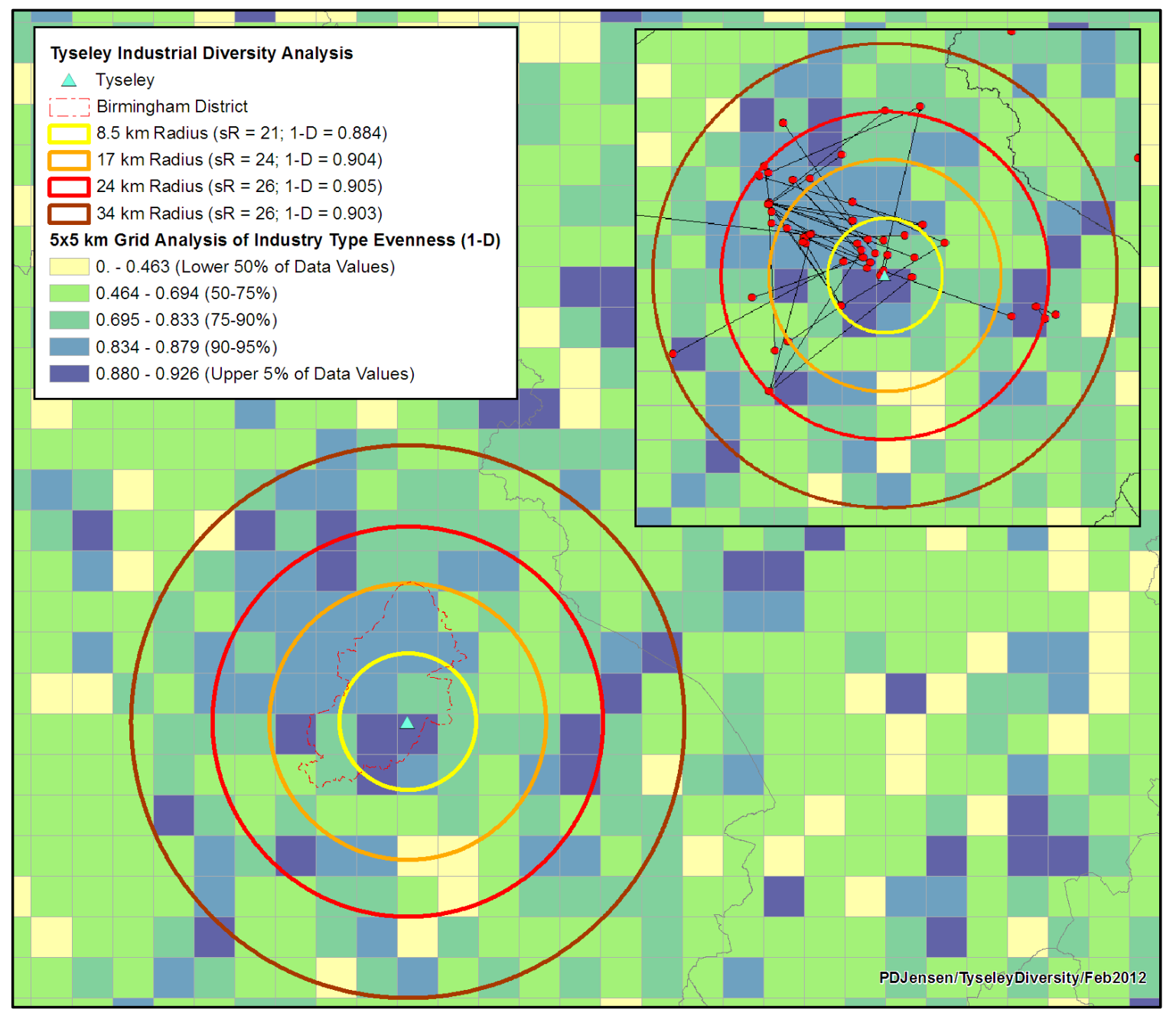

Figure S.4: Application of geospatial industrial diversity mapping

Note: as discussed in the main article text, a practitioner is able to use industrial diversity mapping to pinpoint an area with significant levels of diverse and mature industry (i.e., in the above example, Tyseley within Birmingham). By plotting outwards from this area it is possible to find at what point species richness (sR) plateaus and species evenness (1-D) is at its highest (in the case of Tyseley, this is represented by the red $24 \mathrm{~km}$ data sampling plot). It is argued that this distance represents the optimal cost and environmentally effective area in which a potential symbiotic partner for a given company can be expected to be found. In support of this argument, it can be seen within the inset diagram of Figure S.4 that the vast majority of NISP synergies facilitated in the study area are indeed found within a $24 \mathrm{~km}$ radius of the Tyseley map square. For interest and comparison to the distance at which diversity reaches its peak when plotting outwards from the study site, the dark red, orange and yellow data sampling plots located centrally around Tyseley represent, respectively, the $34 \mathrm{~km}$ average distance physical materials move within NISP brokered synergies in England, half this distance $(17 \mathrm{~km})$ and half this distance again (i.e. $8.5 \mathrm{~km}$ ). This example of the proposed mapping method derives from a strategic resource planning study NISP undertook in 2012. Although the results presented in Figure S.4 are very encouraging, further work is clearly required to verify the value and robustness of the described method for identifying the area from which a local symbiont business partner is most likely to be found. 
Table S.1: Interquartile mean and interquartile range of species richness and 1-D figures for synergy resource types for $5 \mathrm{~km}$ sample sizes and the resource movement radius sample sizes

\begin{tabular}{|c|c|c|c|c|c|c|c|c|c|}
\hline \multirow{2}{*}{$\begin{array}{c}\text { Resource Category } \\
\text { (Synergy Type) }^{a}\end{array}$} & \multirow{2}{*}{$\begin{array}{c}\text { Distance } \\
\text { Mean } \\
\mathrm{km}^{\mathrm{b}}\end{array}$} & \multicolumn{4}{|c|}{5 km Grid Sample Size } & \multicolumn{4}{|c|}{ Radius Sample Size } \\
\hline & & $\begin{array}{c}\text { Mean } \\
s R\end{array}$ & $\begin{array}{c}s R \\
\text { Range }\end{array}$ & $\begin{array}{c}\text { Mean } \\
1-D\end{array}$ & $\begin{array}{c}\text { Range } \\
1-D\end{array}$ & $\begin{array}{c}\text { Mean } \\
s R\end{array}$ & $\begin{array}{c}s R \\
\text { Range }\end{array}$ & $\begin{array}{c}\text { Mean } \\
1-D\end{array}$ & $\begin{array}{c}\text { Range } \\
1-D\end{array}$ \\
\hline Aqueous Sludge & 74 & 9 & 5 & 0.837 & 0.085 & 26 & 0 & 0.818 & 0.053 \\
\hline Ashes \& Slags & 30 & 11 & 6 & 0.881 & 0.039 & 23 & 7 & 0.831 & 0.103 \\
\hline Coatings & 9 & 14 & 2 & 0.873 & 0.070 & 21 & 8 & 0.847 & 0.057 \\
\hline Composite Packaging & 24 & 13 & 6 & 0.827 & 0.160 & 21 & 9 & 0.817 & 0.099 \\
\hline Compost \& Soils & 36 & 6 & 6 & 0.720 & 0.198 & 23 & 4 & 0.786 & 0.111 \\
\hline Foodstuff Inc. Oils & 32 & 9 & 9 & 0.793 & 0.236 & 24 & 5 & 0.836 & 0.070 \\
\hline Fuels $^{c}$ & 54 & 6 & 0 & 0.696 & 0,127 & 26 & 1 & 0.840 & 0.026 \\
\hline Glass & 30 & 11 & 6 & 0.859 & 0.046 & 25 & 2 & 0.856 & 0.066 \\
\hline Infrastructure & 43 & 12 & 11 & 0.828 & 0.230 & 23 & 9 & 0.823 & 0.058 \\
\hline Inorganic Chemicals & 144 & 9 & 4 & 0.836 & 0.430 & 26 & 1 & 0.818 & 0.054 \\
\hline Metals & 44 & 9 & 7 & 0.817 & 0.141 & 23 & 7 & 0.830 & 0.080 \\
\hline Minerals & 33 & 11 & 7 & 0.843 & 0.090 & 25 & 4 & 0.849 & 0.076 \\
\hline Misc. Plastics & 32 & 12 & 6 & 0.853 & 0.078 & 25 & 3 & 0.856 & 0.076 \\
\hline Organic Chemicals & 36 & 13 & 11 & 0.860 & 0.067 & 24 & 4 & 0.861 & 0.085 \\
\hline Paper \& Cardboard & 28 & 9 & 8 & 0.810 & 0.086 & 24 & 4 & 0.855 & 0.127 \\
\hline Rubber & 72 & 12 & 6 & 0.842 & 0.046 & 26 & 1 & 0.827 & 0.044 \\
\hline Textiles & 69 & 12 & 7 & 0.838 & 0.071 & 26 & 3 & 0.831 & 0.123 \\
\hline WEEE & 27 & 11 & 7 & 0.824 & 0.143 & 23 & 4 & 0.858 & 0.063 \\
\hline Wood Products & 28 & 10 & 10 & 0.813 & 0.188 & 24 & 4 & 0.846 & 0.089 \\
\hline All Resources & 34 & 11 & 8 & 0.834 & 0.140 & 24 & 4 & 0.842 & 0.084 \\
\hline 5 km Grid Diversity ${ }^{d}$ & N/A & 4 & 3 & 0.605 & 0.231 & 4 & 3 & 0.605 & 0.231 \\
\hline
\end{tabular}

Notes: ${ }^{a}$ Resource grouping derive from NISP's bespoke waste classification categories. ${ }^{b}$ The distance category refers to the interquartile mean distance that each of the resource types travelled from their point of origin to their point of reuse. ${ }^{\mathrm{c}}$ The fuels resource category refers to materials that were used in power production. ${ }^{d} 5 \mathrm{~km}$ Grid Diversity refers to the mean of all 5 $\mathrm{km}$ grid squares covering England, not solely those containing NISP member companies engaged in synergies. 